Article

\title{
5-Hydroxymethylfurfural (5-HMF) Production from Hexoses: Limits of Heterogeneous Catalysis in Hydrothermal Conditions and Potential of Concentrated Aqueous Organic Acids as Reactive Solvent System
}

\author{
Rodrigo Lopes de Souza, Hao Yu, Franck Rataboul and Nadine Essayem * \\ Institut de Recherche sur la Catalyse et l'Environnement de Lyon, IRCELYON, CNRS, \\ Université Lyon 1, 2 avenue Albert Einstein 69626 Villeurbanne, France; \\ E-Mails: rodrigo.lopes@ircelyon.univ-lyon1.fr (R.L.S.); hao.yu@ircelyon.univ-lyon1.fr (H.Y.); \\ franck.rataboul@ircelyon.univ-lyon1.fr (F.R.) \\ * Author to whom correspondence should be addressed; \\ E-Mail: nadine.essayem@ircelyon.univ-lyon1.fr.
}

Received: 25 July 2012 / Accepted: 22 August 2012 / Published: 13 September 2012

\begin{abstract}
Hydroxymethylfurfural (5-HMF) is an important bio-sourced intermediate, formed from carbohydrates such as glucose or fructose. The treatment at $150-250{ }^{\circ} \mathrm{C}$ of glucose or fructose in pure water and batch conditions, with catalytic amounts of most of the usual acid-basic solid catalysts, gave limited yields in 5-HMF, due mainly to the fast formation of soluble oligomers. Niobic acid, which possesses both Lewis and Brønsted acid sites, gave the highest 5-HMF yield, 28\%, when high catalyst/glucose ratio is used. By contrast, we disclose in this work that the reaction of fructose in concentrated aqueous solutions of carboxylic acids, formic, acetic or lactic acids, used as reactive solvent media, leads to the selective dehydration of fructose in 5-HMF with yields up to $64 \%$ after 2 hours at $150{ }^{\circ} \mathrm{C}$. This shows the potential of such solvent systems for the clean and easy production of 5-HMF from carbohydrates. The influence of adding solid catalysts to the carboxylic acid media was also reported, starting from glucose.
\end{abstract}

Keywords: 5-hydroxymethylfurfural; heterogeneous catalysis; organic acids; glucose; fructose 


\section{Introduction}

Among the organic compounds that can be obtained from biomass, 5-hydroxymethylfurfural (5-HMF) is probably one of the most important platform molecules. Indeed, it can be prepared through catalyzed dehydration of largely available carbohydrates, such as glucose (Scheme I), and transformed into highly valuable intermediates, such as FDCA (2,5-furandicarboxylic acid). Indeed, FDCA presents structural analogies with terephthalic acid (Scheme II) and might replace this carbon fossil-based monomers in polyesters and polyamides synthesis. This is the reason why FDCA is considered as "the sleeping giant" among chemical intermediates issued from renewable carbon [1].

Scheme I. 5-Hydroxymethylfurfural from carbohydrates.

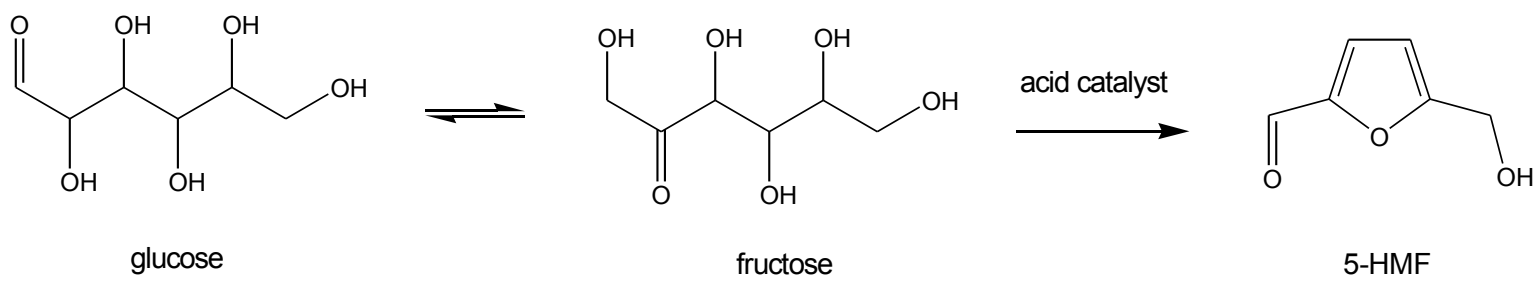

Scheme II. Structural formulas of Terephthalic acid and 2,5-furandicarboxylic acid.

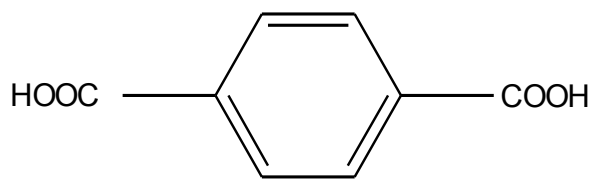

terephthalic acid

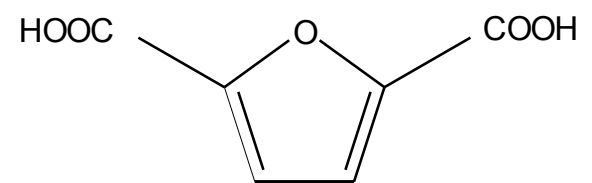

2,5-furandicarboxylic acid

Therefore, extensive research efforts are currently being performed to develop efficient and sustainable methods to prepare 5-HMF. However, up to now, there is still no intensive commercial production of 5-HMF, due certainly to the lack of an efficient and sustainable process to produce 5-HMF from cheap carbohydrates.

In this field, one can say that it is particularly difficult to analyze the literature data due to the wide variety of conditions used (water/organic media, ionic liquids, use of HMF extractive solvent, amounts of extractive solvent/reactive phase, high catalyst/reactant ratio, concentration of sugars, temperature, nature of the carbohydrate, ...). Nevertheless, various aspects of 5-HMF chemistry have been recently reviewed [2-5] and the main features of 5-HMF synthesis from carbohydrates are summarized in the following.

5-HMF is synthesized via acid catalyzed carbohydrate dehydration, generally from monosaccharides such as fructose or glucose, but one can also obtain 5-HMF directly from lignocellulosic raw materials [6]. This synthesis has been known since the end of the $19^{\text {th }}$ century. The difficulties encountered for a selective 5-HMF synthesis in water mean that increasingly complex methodologies have been attempted [7]: anhydrous organic solvents, sub- or supercritical media, biphasic media in a reactive aqueous phase and a 5-HMF extractive solvent immiscible in water, ionic liquids... This is explained by the low 5-HMF selectivity obtained when the reaction is carried out in pure water, due to the uncontrolled re-hydration of the 5-HMF in levulinic and formic acids. Moreover, intermediates or 
the 5-HMF itself may polymerize to produce oligomers, called humins, that are more or less soluble in water [8].

To solve the problems of the low 5-HMF selectivity in the water medium, the following approaches were applied more or less successfully:

i- In situ extraction of 5-HMF from the reaction media to avoid its successive transformation. This was done using a 5-HMF extractive solvent, immiscible in water [6-9]. However, the use of large volumes of solvent could be a serious drawback for further industrial applications. On the other hand, 5-HMF separation from the aqueous media was also reported via steam extraction [10]. One can also mention that the continuous water extraction from the reaction media favors 5-HMF yield [7].

ii- An alternative solution is to perform the reaction in organic/aqueous media or in pure organic solvent. DMSO (Dimethylsulfoxide) is the usual organic solvent for the 5-HMF synthesis. If the glucose dehydration in 5-HMF in pure water is not selective, in DMSO, higher yields (42\%) were reported [9].

iii-Ionic liquids are being increasingly investigated to synthesize 5-HMF. In 2006, Moreau et al. [11] reported the efficient dehydration of fructose into 5-HMF in an ionic liquid, 1-H,3-methyl imidazolium chloride. Using diethyl ether to recover 5-HMF, a yield of $85 \%$ was reported after a few minutes of reaction time at $90{ }^{\circ} \mathrm{C}$.

Metallic chlorides in ionic liquids were reported to be an exceptional system capable to convert glucose in 5-HMF in high yield. In the catalytic system, $\mathrm{CrCl}_{2} / \mathrm{EMIMCl}$, yields in 5-HMF of 62-69\% were reported starting from glucose [12,13]. The efficiency of the catalytic system is ascribed to its ability to isomerize glucose in fructose, a ketohexose, more easily dehydrated. Similar results were obtained with the system $\mathrm{SnCl}_{4} /\left[\mathrm{EMIm} \mathrm{BF}_{4}\right.$ [14]. Ionic liquids combined with La-based catalysts, a Cr-free catalytic system, were also applied for the direct conversion of glucose into 5-HMF with a yield of $24 \%$. Very recently, the addition of others chlorides, $\mathrm{NbCl}_{5}, \mathrm{TaCl}_{5}, \mathrm{VCl}_{3}$, were used in ionic liquids to dehydrate fructose in 5-HMF [15]. The highest yield in 5-HMF was reported over $\mathrm{NbCl}_{5}$. From the authors, the remarkable 5-HMF selectivity obtained with these chlorides could be ascribed to their weak Lewis acidity while strongest Lewis acids would favor side reactions.

From the brief overview presented above, it is clear that the challenge of a selective synthesis of 5-HMF will depend on the acid-basic catalytic system combined with an adequate reaction medium and process. Although many papers deal with carbohydrate dehydration in 5-HMF, only a few gave insights on the catalyst properties which would be favorable to the 5-HMF selective formation. In particular, on the role of the nature and of the strength of the acid sites which would promote a selective dehydration of hexoses into 5-HMF.

Among them, Kuster et al. [16] investigated the role of the $\mathrm{pH}$ of aqueous solution to perform the dehydration of fructose in 5-HMF. They showed that a narrow acidic $\mathrm{pH}$ range (2.7-3.9) could prevent the successive conversion of 5-HMF in levulinic and formic acids. Concerning heterogeneous catalysts, Carlini et al. [17,18] reported the good performances for 5-HMF synthesis of metallic phosphates, which are generally considered as weak Brønsted/Lewis acids. This strengthens well the former conclusions of Kuster [16]. 
On the other hand, although it is expected that Lewis acids might dehydrate carbohydrates, the question of the nature of the acid sites is essential but remains controversial, particularly when water media is concerned. By contrast to the ionic liquids media reported above, the use of Lewis acids in water has, for a long time, been considered as meaningless, due to their unavoidable conversion into Brønsted acids. Again, Carlini et al. [19] first addressed this question via the investigation of zirconium and titanium phosphates, which possess Brønsted and Lewis acid sites. From fructose, in water at $100{ }^{\circ} \mathrm{C}$, the authors reported a selectivity in 5 -HMF of $81 \%$ at relatively high fructose conversion: $52 \%$. From the authors, both Lewis and Brønsted sites would be involved in the fructose dehydration and they reported that the improvement of the Lewis acid strength favored the 5-HMF yield. Later, boric acid was also reported as a weak Lewis acid catalyst active in the aqueous dehydration of fructose into 5-HMF [20]. Boric acid was used in the presence of $\mathrm{NaCl}$. Using the catalytic system, boric acid/ $\mathrm{NaCl}$, and MIBK: methyl isobutyl ketone) as extractive solvent, a yield of $60 \%$ in 5-HMF was achieved from fructose, while a lower one, 14\% was obtained from glucose. Kitano et al. [21] reported that titanate nanotubes were efficient catalysts in the formation of 5-HMF at $120{ }^{\circ} \mathrm{C}$ in water. They showed that while the usual mineral acids were inactive at $120{ }^{\circ} \mathrm{C}$ in water, the titanate nanotubes promoted fructose and glucose dehydration into 5-HMF with yields of $16 \%$ and $14 \%$ respectively. The authors explained this result by the presence of a Lewis acidity associated to effective Brønsted sites on the surface of the titanate nanotubes. Very recently, Nakajima et al. [22] reported that niobic acid was an efficient water-tolerant Lewis acid capable of dehydrating glucose into 5-HMF. The authors claimed that the presence of high amounts of niobic acid are essential to isomerize glucose into fructose, and that the 5-HMF formation would proceed also on the Lewis acid sites. Yields in 5-HMF of 20-25\% were obtained from glucose when equivalent amounts of glucose and $\mathrm{Nb}_{2} \mathrm{O}_{5}$ were used. Note that when niobic acid was treated with phosphoric acid, a higher 5-HMF yield was achieved from glucose: $30-36 \%$, but still using equivalent amounts of catalyst and glucose [22]. Similarly, $\mathrm{TiO}_{2}$ nanoparticles of high surface area were described as efficient Lewis acids for the production of 5-HMF in water from various carbohydrates [23]. Using quantitative amounts of sugar and $\mathrm{TiO}_{2}$, a 5 -HMF yield of $36 \%$ was obtained in water, but with the assistance of microwaves. Finally, it is worth mentioning that hydrated tantalum oxides, $\mathrm{Ta}_{2} \mathrm{O}_{5} \cdot \mathrm{nH}_{2} \mathrm{O}$, pure or treated with $\mathrm{H}_{3} \mathrm{PO}_{4}$, were shown to be as active as the Nb-based catalysts [24]. Yields in 5-HMF of $90 \%$ were recently obtained in a biphasic system.

One can conclude that if the most recent literature underlines the role of Lewis acid sites, not only to isomerize glucose into fructose but also for the fructose dehydration step, the earliest studies rather underlined the role of the Brønsted sites in the carbohydrate dehydration step.

At this stage, the question of the use of a catalytic system capable of isomerizing glucose into fructose appears to be the key point. Accordingly, would it be possible to design a catalytic system which could isomerize glucose into fructose and then dehydrate fructose into 5-HMF? For that, it is essential to clarify which types of sites are involved in each elementary step.

As can be seen from the above, from the recent literature data, it seems that this problem could be solved by using Lewis acids capable of promoting both the glucose-fructose isomerization and fructose dehydration. The efficiency of Lewis acid catalysts such as Sn-Beta zeolite to isomerize glucose into fructose in water was shown by Davis et al. [25]. The authors reported that the aldose-ketose 
isomerization would occur via an intramolecular hydride shift promoted by the Lewis centers, a mechanism close to that promoted by the enzymes.

Currently, glucose isomerization into fructose is a large-scale industrial process, catalyzed by immobilized enzymes [26,27]. Nevertheless, alkali-catalyzed glucose isomerization into fructose has been known since 1895 [28], but $\mathrm{NaOH}$ does not selectively catalyze glucose-fructose isomerization [29]. This isomerization can also be promoted by heterogeneous basic catalysts, such as potassium aluminate [30], alkaline exchanged $\mathrm{X}, \mathrm{Y}$ zeolites and $\mathrm{Mg} / \mathrm{Al}$ hydrotalcite (HDT) [31], metallosilicates substituted by alkaline or yttrium cations [29] or basic hybrid molecular sieves [32]. Correlation between the isomerization activity and the catalyst basicity was reported by Moreau et al. [33] who investigated glucose isomerization by means of aqueous $\mathrm{NaOH}$ solutions of different $\mathrm{pH}$. That was confirmed more recently by S. Lima et al. [29]. Thus, it seems clear that the glucose-fructose isomerization may proceed either by proton transfer (basic catalyzed step) or by hydride transfer (Lewis acid catalyzed step). By contrast, the role of Lewis sites, in the fructose dehydration step, remains questionable from the literature data.

Besides the recent approach consisting of using Lewis acids to isomerize glucose in fructose and to dehydrate the fructose into 5-HMF, another approach consists of using amphoteric catalysts with basic sites to isomerize the glucose and Brønsted acid sites to perform the dehydration. Watanabe et al. [10] reported that $\mathrm{TiO}_{2}$ anatase, which possesses acid and basic sites (in contrast to $\mathrm{TiO}_{2}$ rutile), was shown to convert glucose directly into 5-HMF, while $\mathrm{TiO}_{2}$ rutile did not. Logically, the authors concluded that the glucose conversion into 5-HMF required a preliminary glucose-fructose isomerization promoted by basic sites. In line with this approach, in 2010, Ohara et al. [34] reported the use of a combination of a basic catalyst, HDT, and an acid one, Amberlyst 15, to perform the direct conversion of glucose in 5HMF, but using DMF (dimethyl formamide) as solvent.

To summarize, we would say that the mechanism of dehydration of hexoses in 5-HMF and the nature of the active sites involved in the elementary steps, the isomerization and the dehydration, are not well established. That is probably why, up to now, the design of an efficient catalytic system for the direct conversion of glucose into 5-HMF, in water, has still not been achieved.

As regards the formation of 5-HMF in pure water, by means of a heterogeneous catalyst, one can turn to some reference works. The use of aluminosilicate catalysts to produce 5-HMF from fructose was patented in 1992 [35]. At $145{ }^{\circ} \mathrm{C}$, yields in 5-HMF of 20-32\% were claimed with zeolites and protonic montmorillonite. Niobic acid, niobium or vanadium phosphates have been applied to dehydrate fructose and inulin, giving high yields up to $50 \%$ at $80-100{ }^{\circ} \mathrm{C}$ [36-38]. This is certainly the highest 5-HMF yield reported to date in pure water without the assistance of an extractive solvent. Metal oxides like $\mathrm{ZrO}_{2}$ and $\mathrm{TiO}_{2}$ have been employed under microwave assistance at $200{ }^{\circ} \mathrm{C}$, giving 5 -HMF yields of $30-40 \%$ from fructose [39]. Using mesoporous $\mathrm{TiO}_{2}$ nanoparticles [23], from fructose, a yield of $36 \%$ was obtained in the assistance of microwaves. Starting from glucose, $\mathrm{H}_{3} \mathrm{PO}_{4}$-treated $\mathrm{Nb}_{2} \mathrm{O}_{5}$ was reported to lead to a 5-HMF yield of 30-36\% [22].

In almost all these studies, high conversions of the reactants (especially fructose) were observed but limited yields in 5-HMF were still reported. Moreover, in most of the studies, a quantitative amount of glucose and catalysts were used, combined with the use of a limited volume of water. However, as mentioned above, due to many differences in the experimental conditions used, it is rather difficult to compare the literature data in this field. 
We wish here to report our efforts, on one side of the study, in the preparation of 5-hydroxymethylfurfural with the influence of a large panel of solid catalysts in pure hydrothermal conditions using fructose or glucose as reactant. On the other side we introduce our first results in the use of aqueous concentrated liquid carboxylic acids as an alternative reactive solvent system.

\section{Results and Discussion}

\subsection{Pure Hot Water as Reaction Medium}

We choose in a first set of experiments to study the reactivity of glucose in water in the absence, then in the presence, of various solid catalysts chosen as regards their acid-basic features. First, let us report in Figure 1 the transformation of aqueous solutions of $1 \mathrm{wt} \%$ glucose as a function of temperature. After 2 hours' reaction in batch conditions, temperatures higher than $150{ }^{\circ} \mathrm{C}$ led to an increasing conversion of glucose from $25 \%$ at $180{ }^{\circ} \mathrm{C}$ up to $95 \%$ at $250{ }^{\circ} \mathrm{C}$. Note that only part of the glucose is converted into $5-\mathrm{HMF}$ with a maximum yield of $26 \%$ at $220{ }^{\circ} \mathrm{C}$. A higher temperature, $250{ }^{\circ} \mathrm{C}$, is detrimental for HMF formation, as well as for the formation of other products detected by HPLC, (levulinic acid, formic acids, lactic acids, acetol, mannose...). Indeed, most of the products from glucose transformation at $250{ }^{\circ} \mathrm{C}$ are soluble oligomers, since the TOC analysis has measured a carbon balance higher than $95 \%$ in all experiments. This phenomenon of glucose disappearance and transformation in soluble oligomers is also dependent on the $\mathrm{pH}$ of the aqueous media. Figure $2 \mathrm{a}$ and $2 \mathrm{~b}$ present the progressive disappearance of glucose when the temperature is increased from $150{ }^{\circ} \mathrm{C}$ to $200{ }^{\circ} \mathrm{C}$ at the two $\mathrm{pH}$ values, 1 and 11 . Interestingly, if at the highest temperature, $200{ }^{\circ} \mathrm{C}$, a near complete transformation of glucose into soluble oligomers is observed in either acid or basic aqueous solutions, at the intermediate temperature of $180{ }^{\circ} \mathrm{C}$, the degradation of glucose is slightly more pronounced in the basic conditions. This tendency is confirmed at the lowest temperature, $150{ }^{\circ} \mathrm{C}$ : while the glucose is only slightly converted, $17 \%$, in acidic conditions, half of the initial glucose is consumed at basic $\mathrm{pH}$ with limited yields into 5-HMF and other products detectable by HPLC. This suggests, that at $150{ }^{\circ} \mathrm{C}$, at least the formation of undetermined soluble oligomers, not detected by HPLC, proceeds faster via a basic catalyzed mechanism compared to an acidic one.

Figure 1. Glucose conversion and 5-HMF yield in water as a function of the temperature.

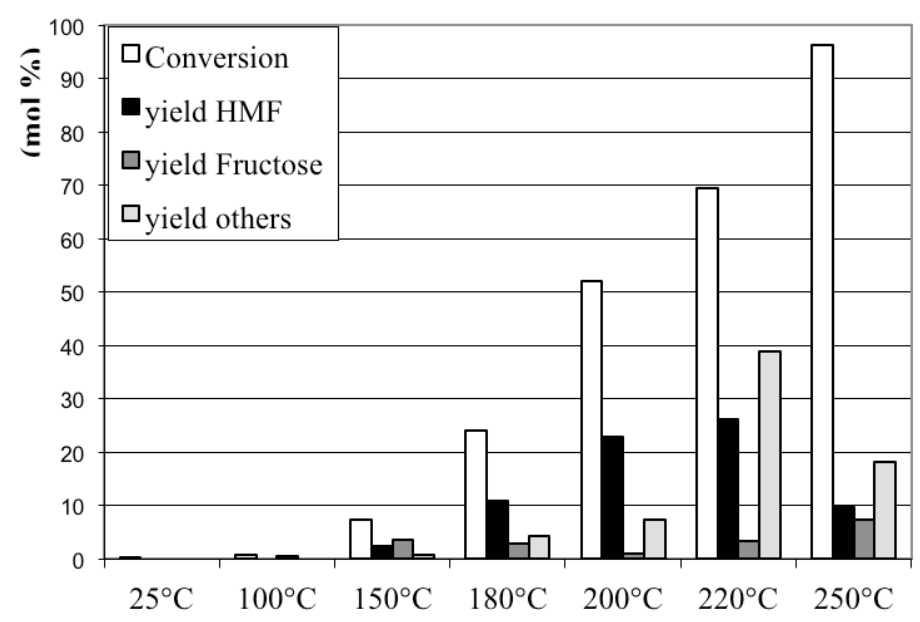

Conditions: batch, $1 \%$ wt glucose in water, without catalyst: reaction time 2 hours. 
Figure 2. Glucose conversion in aqueous media: temperature and $\mathrm{pH}$ dependences.

a. Glucose conversion in acidic aqueous media $(\mathrm{pH}=1, \mathrm{HCl})$ at $150{ }^{\circ} \mathrm{C}, 180{ }^{\circ} \mathrm{C}$ and $200^{\circ} \mathrm{C}$.

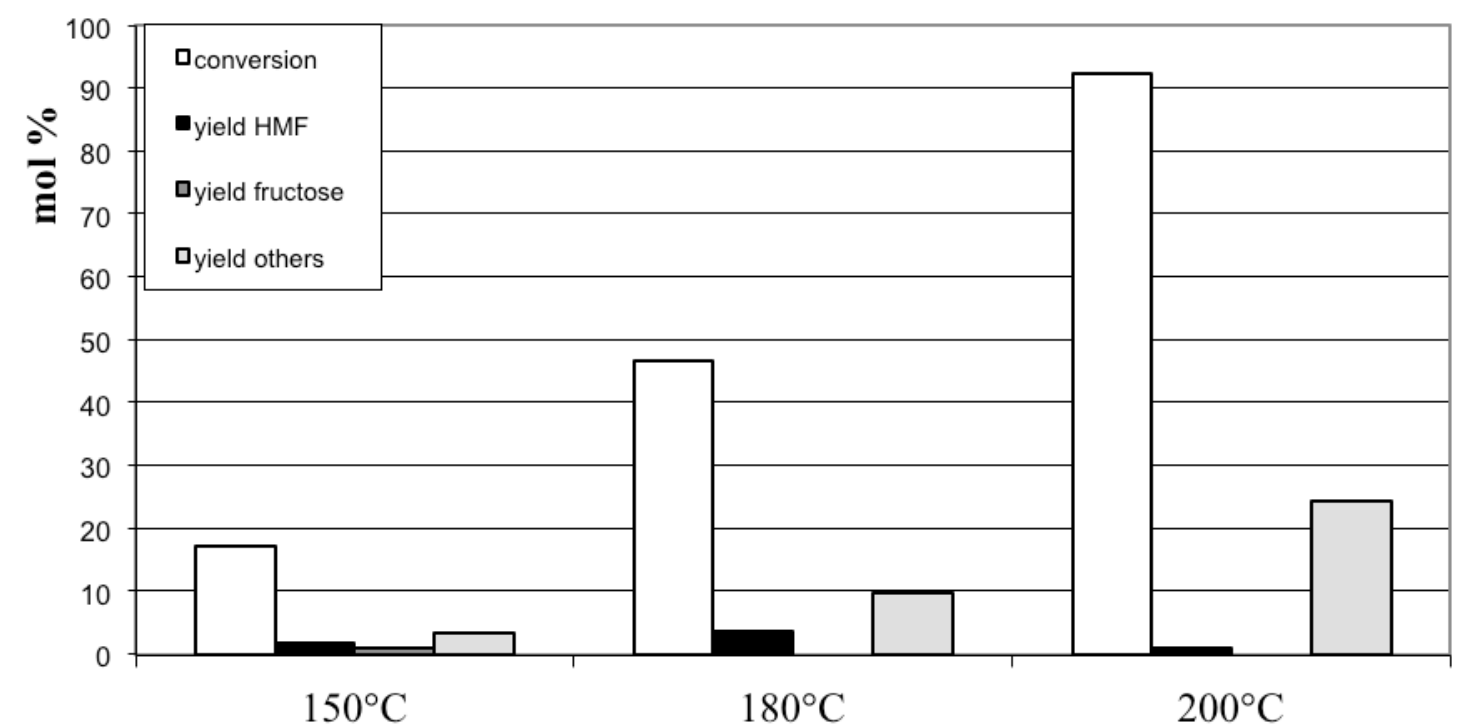

Conditions: batch, $1 \% \mathrm{wt}$ glucose in water, $\mathrm{pH}=1(\mathrm{HCl})$ : reaction time 2 hours.

b. Glucose conversion in basic aqueous media $(\mathrm{pH}=11, \mathrm{NaOH})$ at $150{ }^{\circ} \mathrm{C}, 180{ }^{\circ} \mathrm{C}$ and $200^{\circ} \mathrm{C}$.

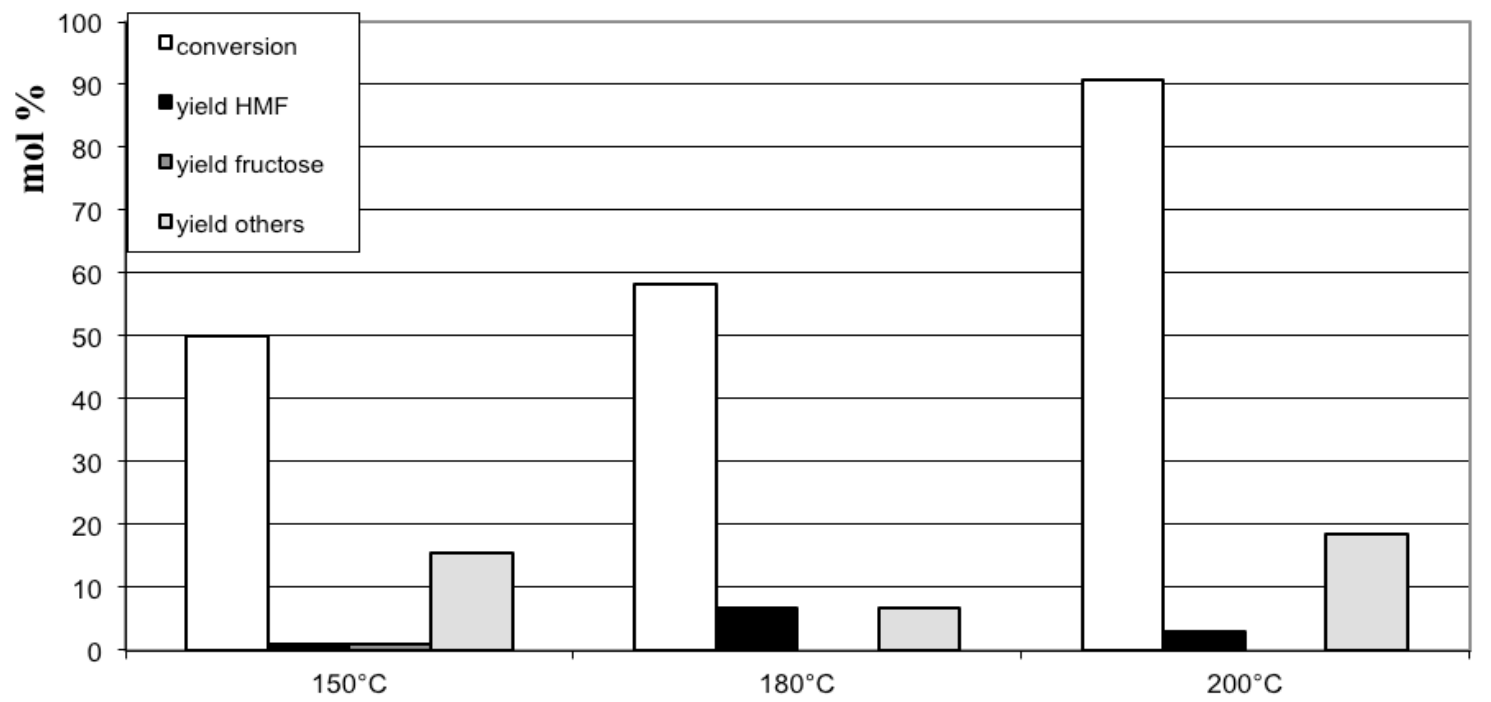

Conditions: batch, $1 \% \mathrm{wt}$ glucose in water, $\mathrm{pH}=11(\mathrm{NaOH})$ : reaction time 2 hours.

Starting from fructose, the influence of the $\mathrm{pH}$ value was investigated in more detail at the lowest temperature, $150{ }^{\circ} \mathrm{C}$ (Figure 3). In neutral condition ( $\mathrm{pH} 7$ ), fructose was not converted: neither was glucose. At higher $\mathrm{pH}$ values, fructose is more reactive than glucose, and one third of the initial fructose was isomerized into glucose. As expected, the main differences between glucose and fructose are observed in acidic condition. In acidic media, by contrast to glucose, an almost total fructose conversion was observed at $\mathrm{pH} 1$, yielding $27 \%$ of 5-HMF. A fine control of the $\mathrm{pH}$ value evidences the close dependence of the 5-HMF yield with the $\mathrm{pH}$ value in agreement with the earlier work of 
Kuster [16]: the maximum yield, 38-43\%, was obtained between $\mathrm{pH} 1.5$ and 2.15, a pH range slightly lower than that determined by Kuster. Once the $\mathrm{pH}$ reached 2.9, the fructose remains un-converted up to $\mathrm{pH} 10$.

Figure 3. Fructose conversion at $150{ }^{\circ} \mathrm{C}$ in aqueous solutions of various $\mathrm{pH}$.

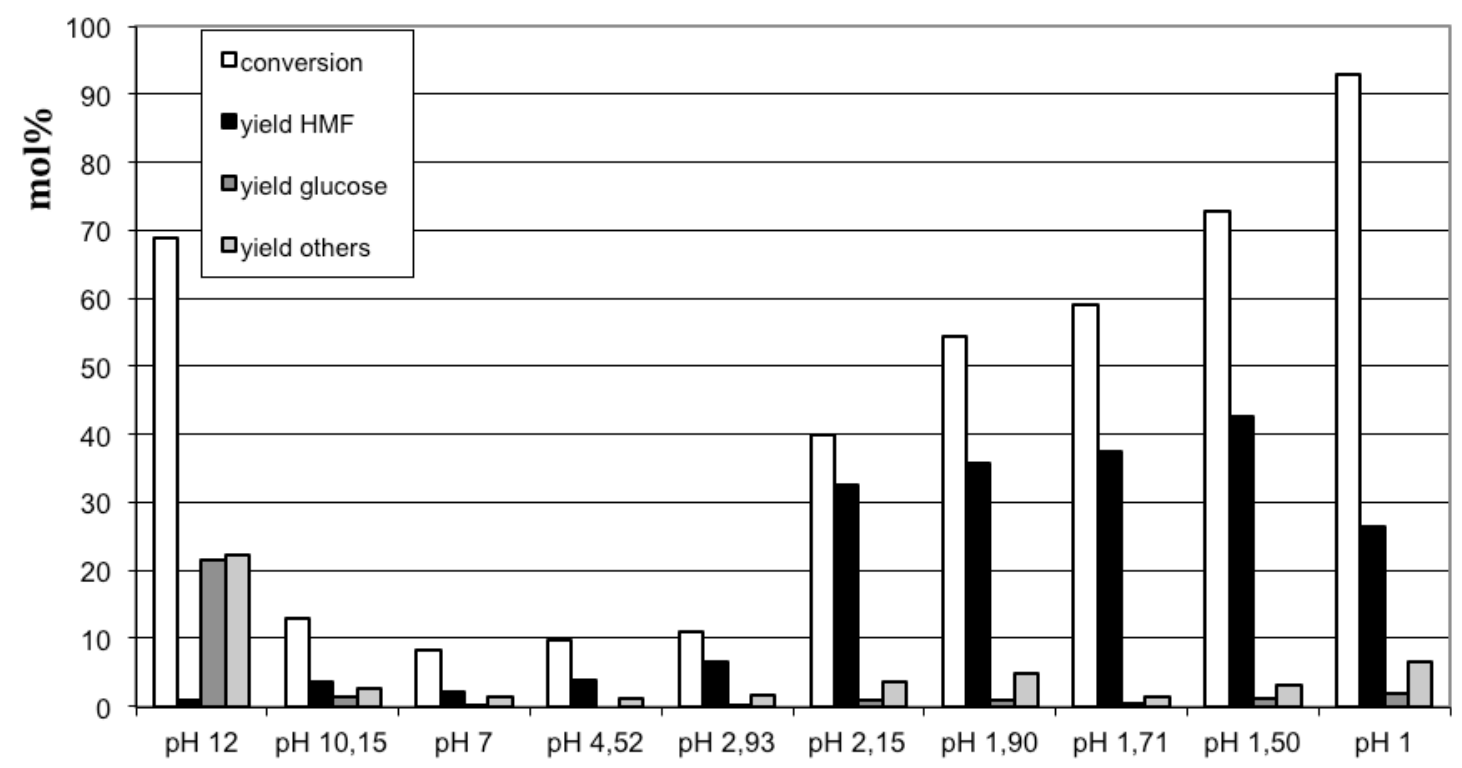

Conditions: Batch, $1 \% \mathrm{wt}$ Fructose in water, $150^{\circ} \mathrm{C}$, reaction time 2 hours acidic $\mathrm{pH}$ : $\mathrm{HCl}$ addition, basic $\mathrm{pH}: \mathrm{NaOH}$ addition.

Since, in neutral conditions, the conversion of glucose and fructose is limited at $150{ }^{\circ} \mathrm{C}$ after $2 \mathrm{~h}$ of reaction, we choose these conditions to evaluate a large panel of solid catalysts susceptible to promoting the formation of HMF. The selected catalysts evaluated here are well known for their different acid-base features, some of them are commercial catalysts, others have been optimized for different catalytic applications investigated in our group, but their efficiency in this reaction has never been reported or compared in the literature in equivalent aqueous reaction conditions, with catalytic amount of solid, $5 \mathrm{wt} \% /$ sugar. Different Brønsted acid catalysts were selected: a strong Brønsted acid, $\mathrm{Cs}_{2} \mathrm{HPW}_{12} \mathrm{O}_{40}$, and commercial zeolites H-ZSM-5 $(\mathrm{Si} / \mathrm{Al}=40)$ and $\mathrm{H}-\mathrm{Y}(\mathrm{Si} / \mathrm{Al}=15)$ which are Brønsted acids of moderate acid strength. Niobic acid (amorphous hydrated niobium oxide from CBMM (Companhia Brasileira de Metalurgia e Mineração), $\mathrm{NbO}(\mathrm{OH})_{3}$ from TGA analysis: abbreviated $\mathrm{NbOH}$ in the following) which was reported in the literature to be an efficient catalyst for fructose dehydration was also studied here. Niobic acid modified with $\mathrm{H}_{3} \mathrm{PO}_{4}$ and $\mathrm{H}_{3} \mathrm{PW}_{12} \mathrm{O}_{40}$ were also evaluated as $\mathrm{Nb}$-based oxide with enhanced Brønsted acidity. Amphoteric supports, such as $\mathrm{ZrO}_{2}$ and $\mathrm{Al}_{2} \mathrm{O}_{3}$, as well as their corresponding hydroxides, $\mathrm{ZrOH}$ and Boehmite were also tested. Zirconia, modified with $\mathrm{Cs}$ ( $\mathrm{ZrCs}$ ) or $\mathrm{Mg}$ ( $\mathrm{ZrMg}$ ), aimed to improve the zirconia basicity, was also evaluated by comparison to un-modified zirconia. Zirconium phosphate $(\mathrm{ZrP})$ was also included in the list, already described as a weak solid acid, efficient in fructose dehydration [36]. Sn-Beta and tungstated zirconia, $\mathrm{WO}_{3} / \mathrm{ZrO}_{2}(\mathrm{ZrW})$ were chosen according to their pronounced Lewis acidity, still effective in water [40]. Finally, a strong solid base, $\mathrm{MgLaO}$ [41], was evaluated.

Figure 4 represents the glucose conversion and 5-HMF yield obtained in the presence of the different catalysts presented above. 
Figure 4. Glucose conversion in aqueous media at $150{ }^{\circ} \mathrm{C}$ in the presence of various acid-basic solid catalysts together with amphoteric $\mathrm{Zr}$ and Al-based solids.

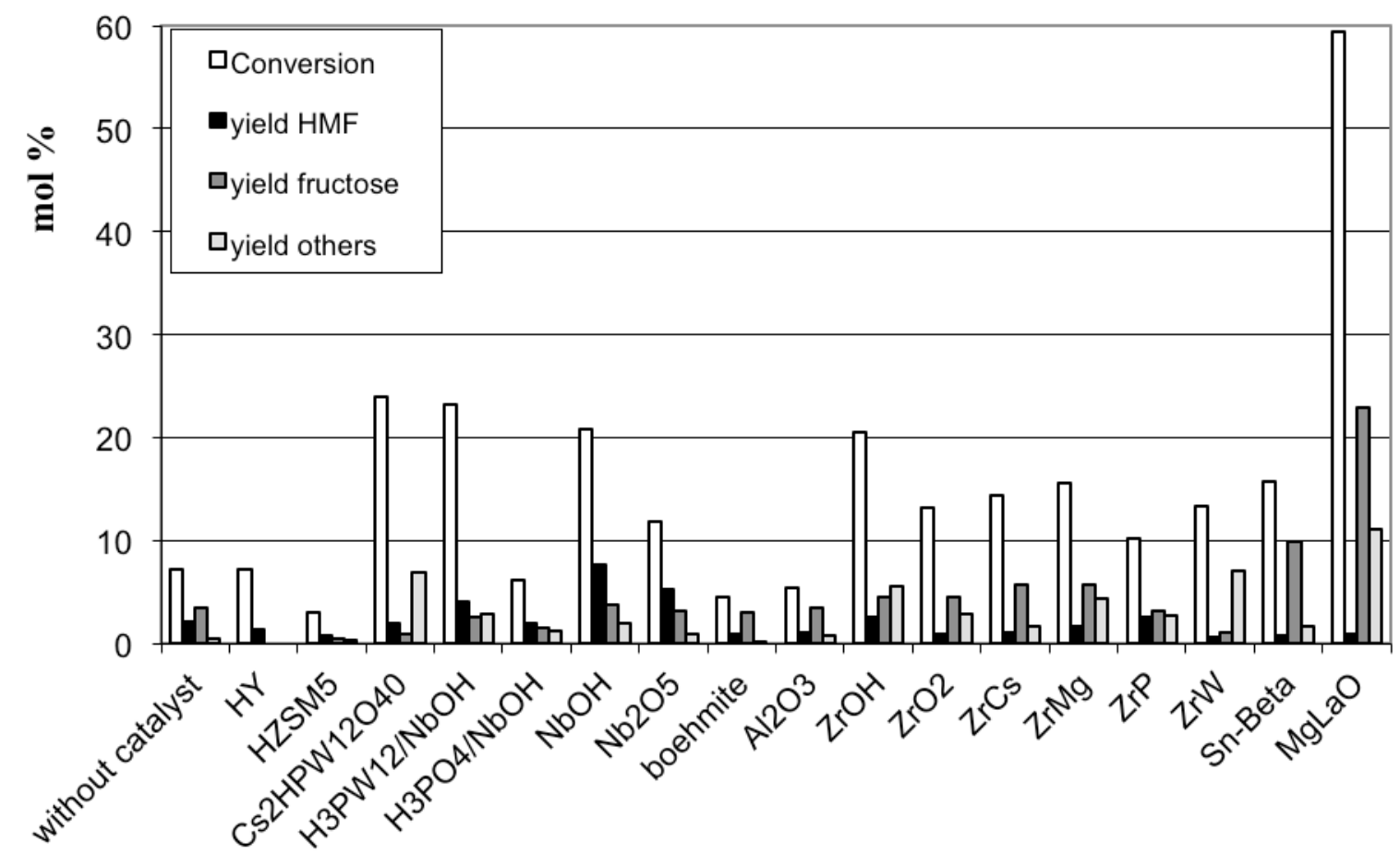

Conditions: batch, $1 \% \mathrm{wt}$ glucose in water, solid catalyst: $5 \mathrm{wt} \%, \mathrm{~T}=150{ }^{\circ} \mathrm{C}$ : reaction time 2 hours.

We can clearly see that most of the catalysts present a low activity in the glucose conversion with a limited yield in 5-HMF, except the basic mixed oxide, $\mathrm{MgLaO}$, which only catalyses the glucose isomerization with a conversion of $60 \%$ and a yield into fructose of $23 \%$. This result shows the remarkable performance of this mixed oxide to isomerize glucose into fructose, compared to the other basic materials $\mathrm{ZrCs}$ and $\mathrm{ZrMg}$ [42]. Note that among the solid acids characterized by pronounced Lewis acids, $\mathrm{ZrW}$ and Sn-Beta, only Sn-Beta produces fructose from glucose, with a lower yield compared to $\mathrm{MgLaO}, 10 \%$ vs. $23 \%$. The lack of isomerization activity of $\mathrm{ZrW}$ might be ascribed to a too-fast degradation of fructose when contacting the catalyst surface. Among the amphoteric solids, the Al-based materials are particularly inert while the $\mathrm{Zr}$ and $\mathrm{Nb}$-based supports are more active. $\mathrm{NbOH}$ and $\mathrm{NbOH}_{400}\left(\mathrm{NbOH}\right.$ calcined at $\left.400{ }^{\circ} \mathrm{C}\right)$ led to the highest yield in 5-HMF among all the tested catalysts. On the other hand, the promotion of $\mathrm{NbOH}$ with $\mathrm{H}_{3} \mathrm{PO}_{4}$ or $\mathrm{H}_{3} \mathrm{PW}_{12} \mathrm{O}_{40}$ did not increase the 5-HMF yield. The performances of $\mathrm{NbOH}$ for the formation of 5-HMF was recently ascribed to its Lewis acidity, which would catalyze the glucose-fructose isomerization [21]. A comparison of $\mathrm{NbOH}$ and $\mathrm{NbOH}_{400}$ as regards their Lewis/Brønsted acidity and their activity in 5-HMF formation would rather suggest that 5-HMF is favored when the adequate Brønsted to Lewis acid sites balance is present on the catalyst surface. Indeed, from their infrared spectra of pyridine adsorption (Figure 5), $\mathrm{NbOH}$ presents a higher Brønsted to Lewis acid sites ratio compared to $\mathrm{NbOH}_{400}$, the latter solid being less active in the formation of 5-HMF. A deeper investigation is required to strengthen these remarks. 
Figure 5. Infrared spectra of pyridine adsorption on $\mathrm{NbOH}$ then vacuum treated at $150{ }^{\circ} \mathrm{C}$.

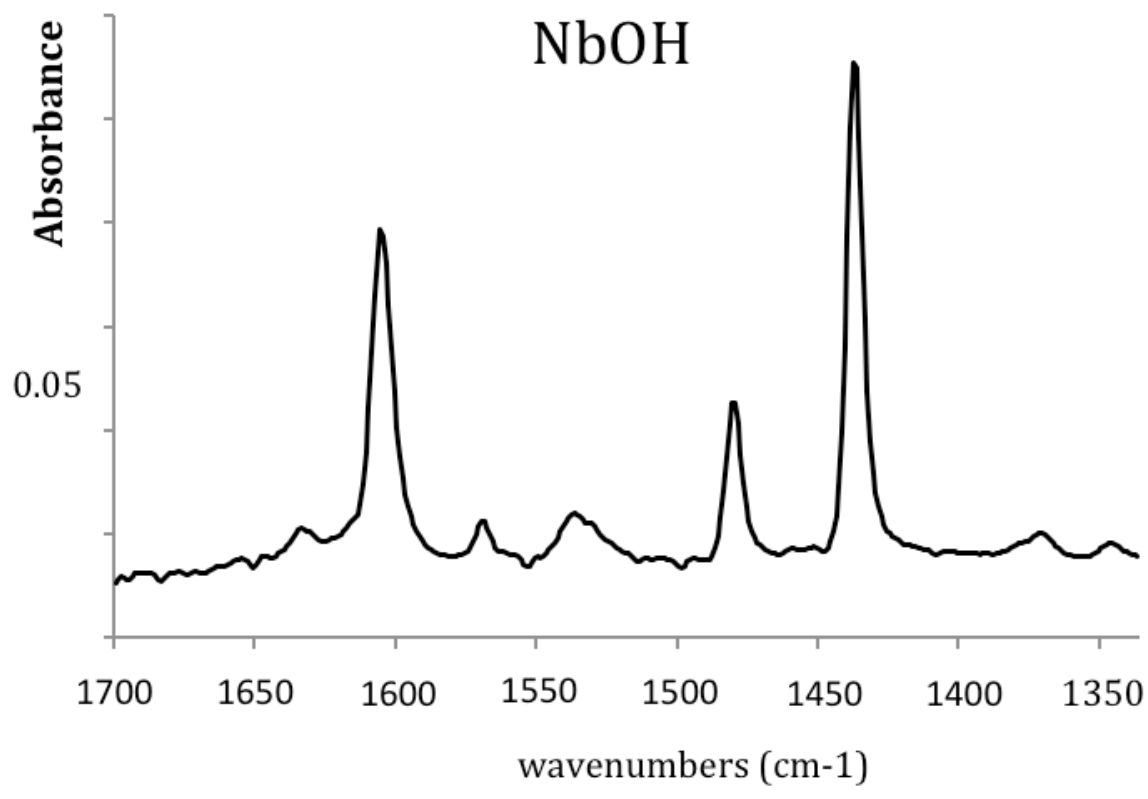

The heteropolyacid $\mathrm{Cs}_{2} \mathrm{HPW}_{12} \mathrm{O}_{40}$, possessing the strongest Brønsted acidity within the series, gave the highest glucose conversion, but with a very low 5-HMF yield, explained by its rehydration in levulinic and formic acid, the main products detected by HPLC. Note that the protonic zeolites H-Y and H-ZSM5 are completely inactive in the present conditions.

Starting from fructose, only a few selected solid catalysts were evaluated at $150{ }^{\circ} \mathrm{C}: \mathrm{Cs}_{2} \mathrm{HPW}_{12} \mathrm{O}_{40}$ $(\mathrm{Cs} 2 \mathrm{H})$ and $\mathrm{ZrW}$, a Brønsted and Lewis solid acid, and the most active solid in 5-HMF formation, $\mathrm{NbOH}$ (Figure 6). The acidic properties of the selected catalysts are well characterized by pyridine adsorption, monitored by infrared spectroscopy: $\mathrm{Cs}_{2} \mathrm{HPW}_{12} \mathrm{O}_{40}$ is a pure solid Brønsted acid, while $\mathrm{ZrW}$ is a marked Lewis acid solid [40]. $\mathrm{NbOH}$ presents both Brønsted and Lewis sites (Figure 5). Note that $\mathrm{NbOH}_{400}$ is characterized by a lower Brønsted/Lewis acid sites balance, as mentioned above. As regards their acid strength, established by $\mathrm{NH}_{3}$ adsorption, followed by calorimetry, the following ranking was obtained: $\mathrm{Cs}_{2} \mathrm{HPW}_{12} \mathrm{O}_{40}>\mathrm{ZrW} \sim \mathrm{NbOH}$, based on the respective heats of $\mathrm{NH}_{3}$ adsorption of 200 $\mathrm{kJ} \cdot \mathrm{mol}^{-1}\left(\mathrm{Cs}_{2} \mathrm{HPW}_{12} \mathrm{O}_{40}\right), 160 \mathrm{~kJ} \cdot \mathrm{mol}^{-1}(\mathrm{ZrW}), 150 \mathrm{~kJ} \cdot \mathrm{mol}^{-1}(\mathrm{NbOH})$.

In the presence of catalytic amount of solid catalyst ( $5 \mathrm{wt} \%$ /sugar), we note a significant increase of the fructose conversion compared to glucose with $\mathrm{ZrW}$ and $\mathrm{NbOH}$, and less significantly with the pure Brønsted solid acid (Figure 6). However, the 5-HMF yield is still not favored, lower than 10\%.

Apparently, the best catalyst evaluated here seems to be niobic acid, $\mathrm{NbOH}$, in agreement with the literature data $[17,43]$. Therefore, we decided to study further this catalyst because of some observed discrepancies from the literature data dealing with the use of niobic acid to dehydrate hexoses because the experimental conditions used were somewhat far from the usual catalytic ones. In particular, it seems important to address the role of the high catalyst/reactant ratio applied both in batch conditions $[22,24,36]$ and in a continuous-recycling reactor [43]. 
Figure 6. Fructose conversion in aqueous media at $150{ }^{\circ} \mathrm{C}$ in the presence of $\mathrm{Cs}_{2} \mathrm{HPW}_{12} \mathrm{O}_{40}, \mathrm{ZrW}$ and $\mathrm{NbOH}$.

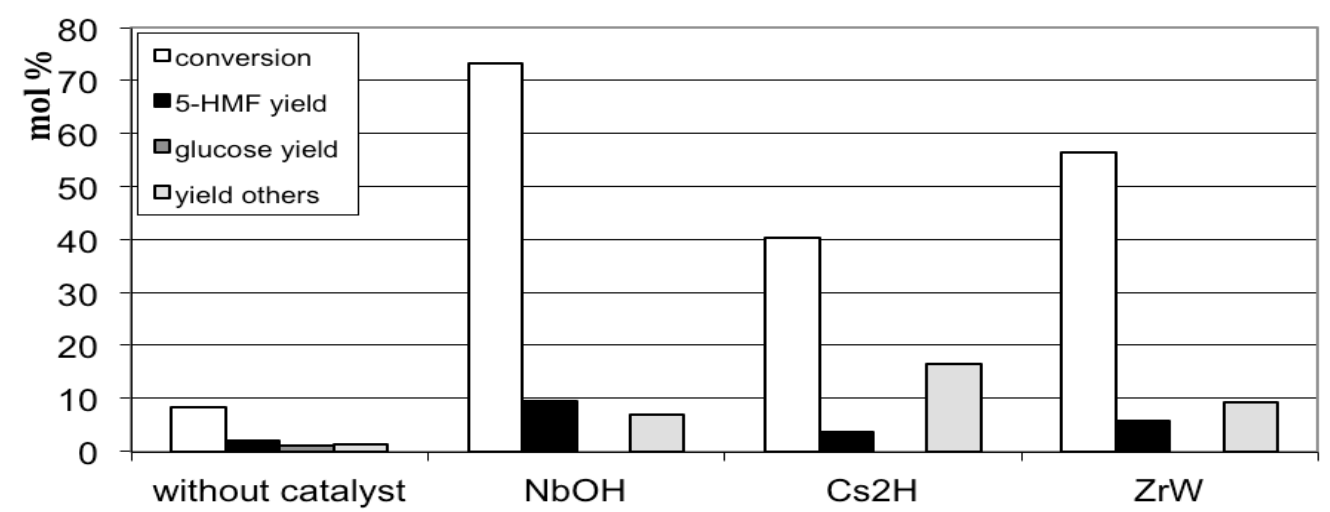

Conditions: batch, $1 \% \mathrm{wt}$ fructose in water, catalysts: $5 \mathrm{wt} \%$, reaction time 2 hours, $\mathrm{T}=150{ }^{\circ} \mathrm{C}$.

We investigated first the influence of the temperature starting from glucose and fructose in the presence of $\mathrm{NbOH}$. From glucose (Figure 7), with catalytic amount of $\mathrm{NbOH}$, a temperature of $250{ }^{\circ} \mathrm{C}$ was required to totally convert glucose. Glucose is principally transformed into soluble oligomers, undetected by HPLC analysis, and the maximum yield in 5-HMF: $16 \%$, was obtained at $200{ }^{\circ} \mathrm{C}$. Starting from fructose (Figure 8), the highest conversion (92\%) and yield (18\%) were reached at a lower temperature of $180{ }^{\circ} \mathrm{C}$. Similarly, fructose is mainly converted into soluble oligomers. It is noteworthy that higher 5-HMF yields were obtained in pure water: $26 \%$ at $220{ }^{\circ} \mathrm{C}$ (Figure 1). The main differences between the present studies and those reported in the literature concerned the catalyst/reactant ratio kept in catalytic proportion in the present study. Figure 9 represents the influence of the amount of niobic acid catalyst for the reaction at $150^{\circ} \mathrm{C}$ for 2 hours. We see that, as expected, the glucose conversion increases up to $80 \%$ when the catalyst amount was raised to $100 \mathrm{wt} \%$, referring to the amount of glucose. A parallel increase of the 5-HMF yield was observed up to $28 \%$. These values are more in line with the 5-HMF yield reported in the literature.

Figure 7. Glucose conversion in aqueous media in the presence of $\mathrm{NbOH}$ as a function of the temperature.

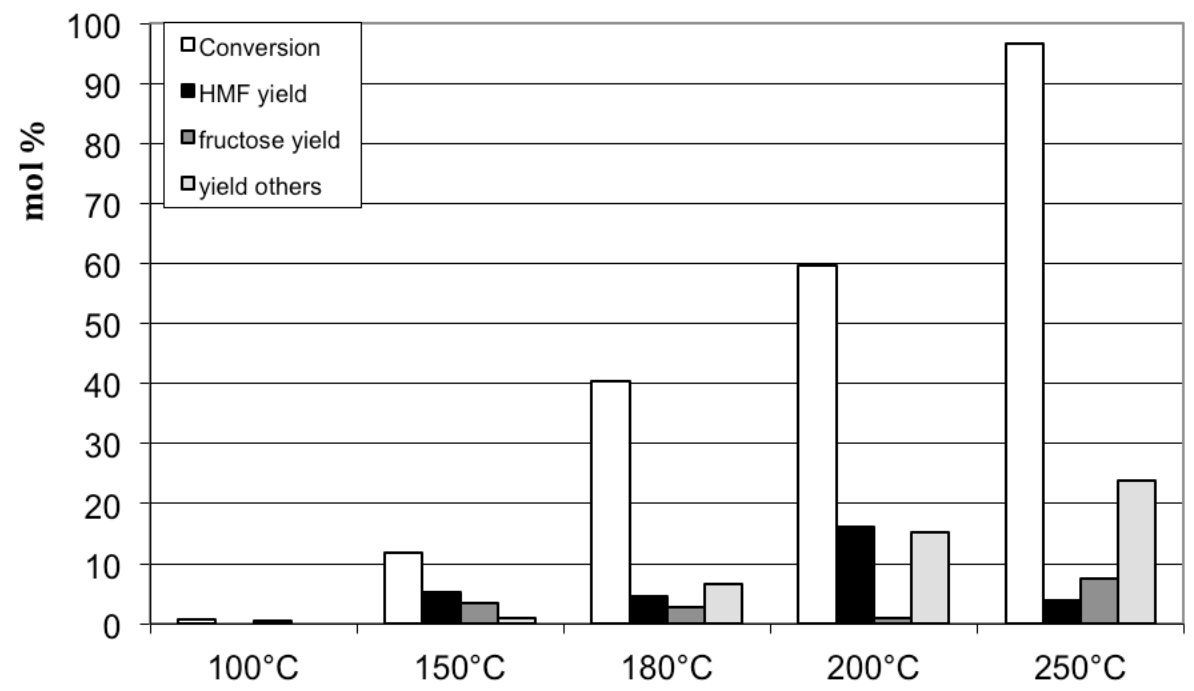

Conditions: batch, $1 \%$ wt glucose in water, $\mathrm{NbOH}: 5 \mathrm{wt} \%$, reaction time: 2 hours. 
Figure 8. Fructose conversion in aqueous media at $150{ }^{\circ} \mathrm{C}$ in the presence of $\mathrm{NbOH}$ as a function of the temperature.

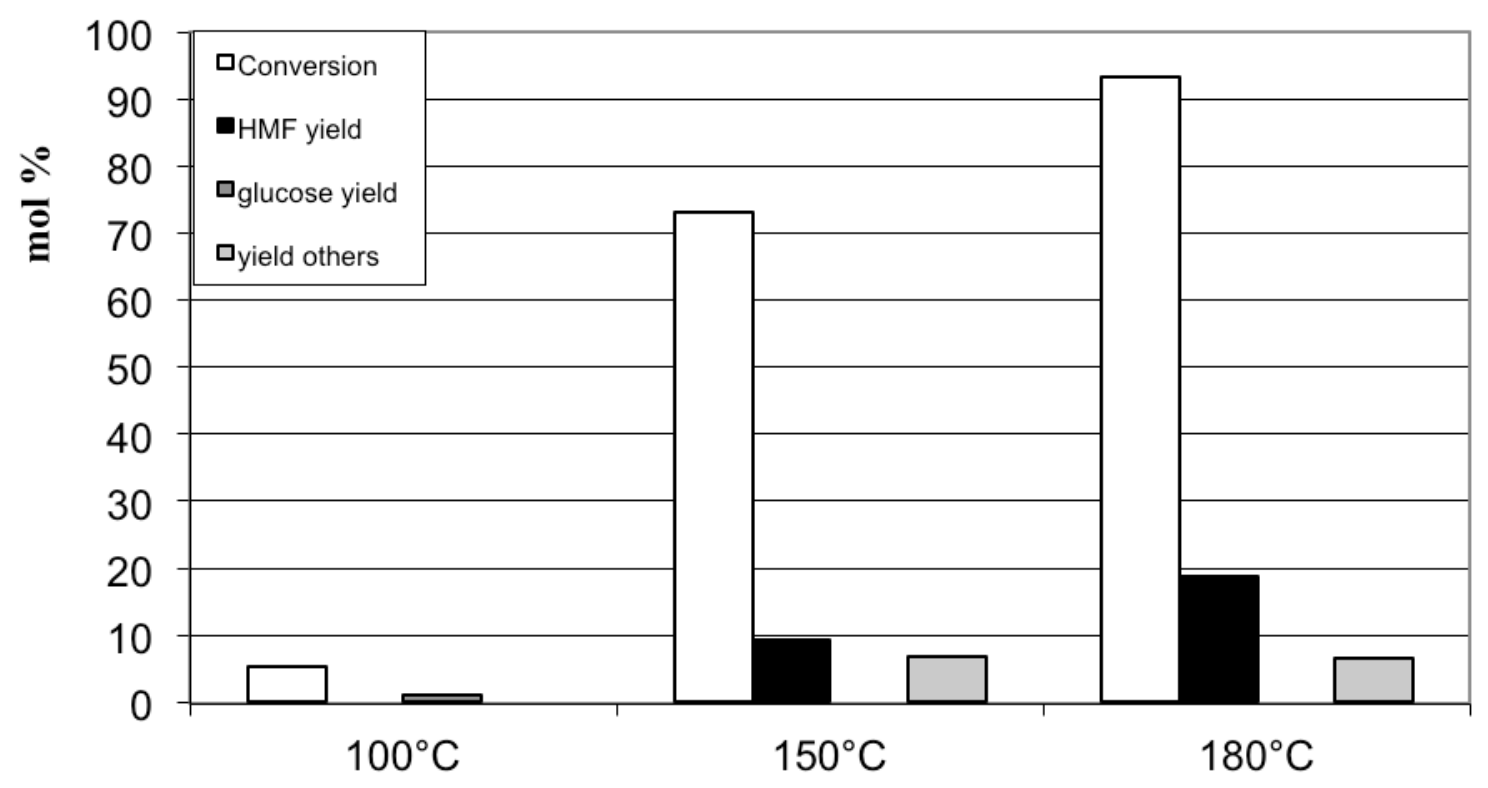

Conditions: batch, $1 \% \mathrm{wt}$ fructose in water, $\mathrm{NbOH}: 5 \mathrm{wt} \%$, reaction time 2 hours.

Figure 9. Glucose conversion in water in the presence of increasing amounts of $\mathrm{NbOH}$.

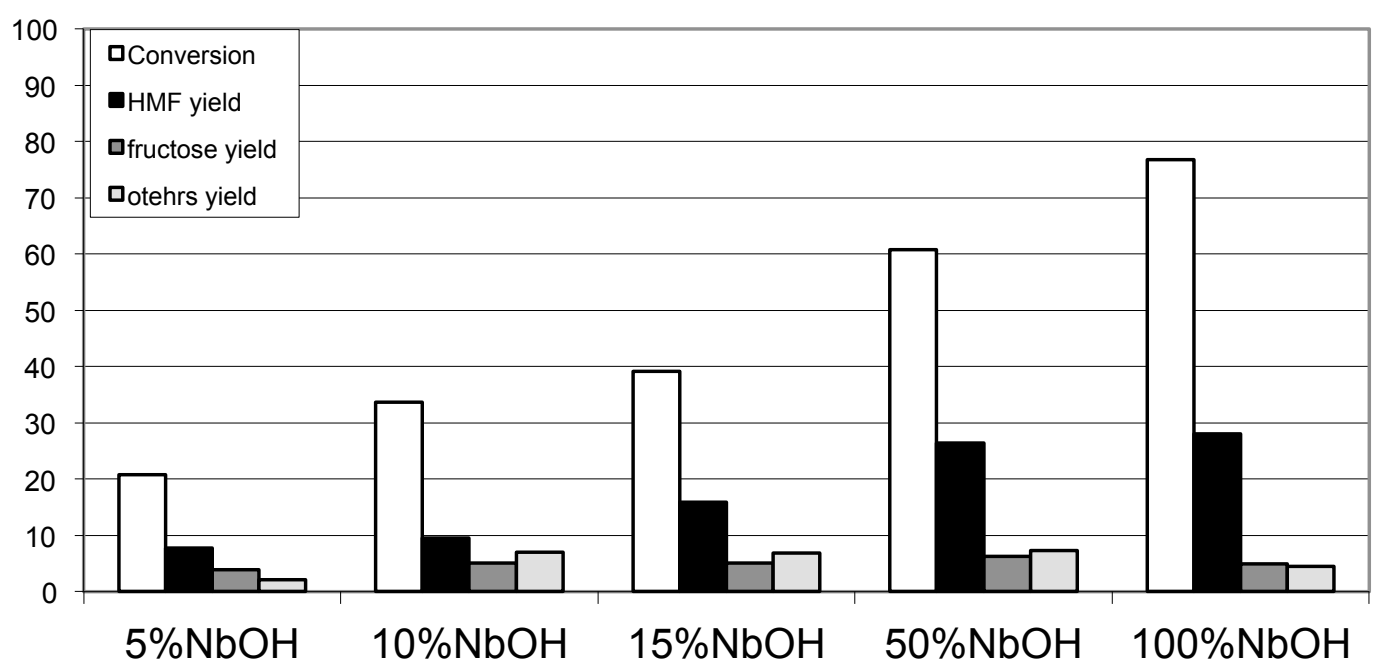

Conditions: batch, $1 \% \mathrm{wt}$ glucose in water, reaction time $=2 \mathrm{~h}, \mathrm{NbOH}: 5-100 \mathrm{wt} \% /$ glucose, $\mathrm{T}=150^{\circ} \mathrm{C}$.

The results described above as well as those from literature definitively show that pure water is not an easy medium for 5-HMF production. Indeed, to have a significant conversion of either glucose or fructose, many solid acid catalysts are active but none of them form 5-HMF selectively. Whatever the catalytic system employed so far, undesired side-reactions leading to a mixture of levulinic and formic acids and mainly oligomeric by-products soluble in water are always observed. $\mathrm{NbOH}$ is certainly one of the most efficient solid acids to produce 5-HMF from aqueous glucose or fructose solutions, but its effect, when used in catalytic amounts, is limited. As a first conclusion, we can say that the glucose and fructose conversion in hot water is a complex process leading easily to the formation of soluble 
water soluble products of difficult identification. The expected product 5-HMF can be obtained only in a limited amount, whatever the nature of the solid used in catalytic amount. In the presence of a solid catalyst in pure water, we did not succeed in producing 5-HMF in a yield equivalent to the one obtained in an aqueous medium where the $\mathrm{pH}$ value is finely tuned between 1.5 and 1.9. 5 -HMF yields higher than $40 \%$ were obtained in such homogeneous conditions.

The lack of selectivity in the aqueous media is at the origin of the use of extracting organic solvents, insoluble in water, making bi-phasic systems able to avoid this over-reactivity of 5-HMF (see Introduction). By curiosity, we evaluated whether the addition of a 5-HMF extraction solvent in the reaction media might significantly increase the yield in 5-HMF. Thus, experiments were performed in our standard conditions $\left(150{ }^{\circ} \mathrm{C}, 2 \mathrm{~h}\right.$ of reaction, $1 \mathrm{wt} \%$ glucose, $5 \mathrm{wt} \%$ of $\left.\mathrm{NbOH}\right)$, but half of the water was replaced by MIBK (methyl isobutyl ketone) or ethyl ether. From Figure 10, we can see that the yield of 5-HMF was not improved, probably due to the partition of 5-HMF between the water and the organic extraction solvent. Probably a large excess of organic solvent is required in order to achieve significant results.

Figure 10. Glucose conversion in water at $150{ }^{\circ} \mathrm{C}$ in the presence of $\mathrm{NbOH}$ : influence of extractive solvent addition: MIBK and diethyl ether.

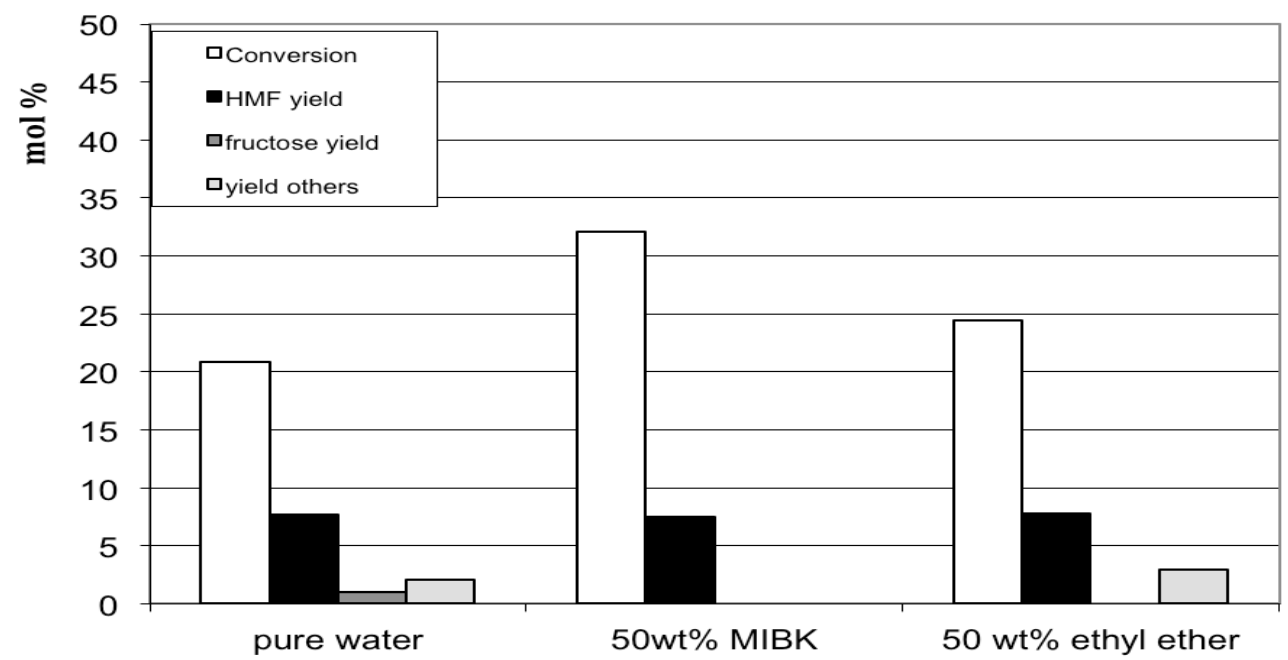

Conditions: Batch conditions, fructose $1 \% \mathrm{wt}, 50 \mathrm{wt} \%$ of extractive organic solvent in water, $150{ }^{\circ} \mathrm{C}, 2$ hours, $5 \mathrm{wt} \% \mathrm{NbOH}$.

Another approach is the use of pure or aqueous organic solvent as reaction medium, which can modify the properties of the aqueous medium and have a positive effect on 5-HMF selectivity. In an effort to find an original and convenient medium to produce 5-HMF, we evaluated liquid carboxylic acids as potential candidates. These are environmentally-friendly solvents produced at low cost, and for some, from renewable resources, and widely used in the chemical industry. As far as we know, only a very few examples of this system have been reported for this application and the earliest studies have reported the use of catalytic amounts of organic acids such as formic, acetic, oxalic or levulinic acids $[44,45]$. In these conditions, limited yields into 5-HMF were obtained, explained by the too-weak acidity of these organic acids compared to $\mathrm{H}_{2} \mathrm{SO}_{4}$ or $\mathrm{HCl}$. 
We wish now to report our first results on the reactivity of fructose and glucose in concentrated aqueous solutions of organic acids, disclosed recently as efficient and clean media to directly produce 5-HMF [46].

\subsection{Concentrated Aqueous Organic Acids Solutions as Reaction Medium}

As a complement to the studies reported above on the 5-HMF formation in pure water in the presence of various solid catalysts, here we report the unexpected efficiency of concentrated aqueous solutions of organic acids used in the absence of added strong acid catalyst, to form directly 5-HMF from fructose, without assistance of an extractive solvent. Then, our first attempts to add solid catalysts to this medium will be presented.

The reactions were still performed in our standard conditions, at $150{ }^{\circ} \mathrm{C}$ for 2 hours, with a solution of $20 \mathrm{wt} \%$ of organic acid in water and $1 \mathrm{wt} \%$ of hexose. In contrast to the study cited above where low concentrations $(\sim 1 \%)$ of organic acids were evaluated $[44,45]$, we decided to perform the reactions in concentrated aqueous organic acid solutions as a reactive solvent system to convert the hexoses thus far from the use of catalytic amounts of organic acid.

First, Figure 11 discloses the unexpected efficiency of a concentrated solution of lactic acid, $20 \mathrm{wt} \%$, to form 5-HMF in a high yield (50\%) starting from fructose. This 5-HMF yield seems to be at least equivalent to the best 5-HMF yield reported in the literature, without the help of an extractive solvent [36-38], but definitively far above the best results obtained in pure hot water reported above. By contrast, this medium did not convert glucose into 5-HMF in equivalent conditions. Then, these results prompted us to carry out experiments with various carboxylic acids in water solutions, starting from fructose (Figure 12).

Figure 11. Glucose and fructose conversion in 5-HMF using a concentrated aqueous solution of lactic acid as reactive solvent.

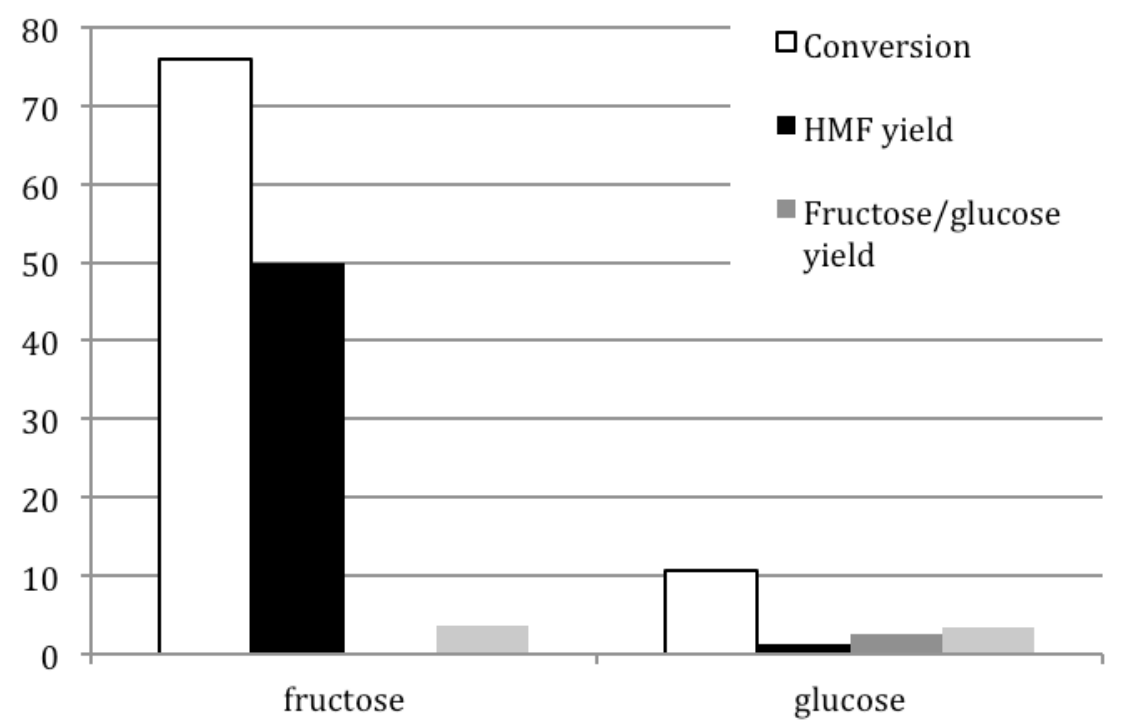

Conditions: Batch conditions, hexoses $1 \% \mathrm{wt}, 20 \mathrm{wt} \%$ lactic acid in water, $150{ }^{\circ} \mathrm{C}, 2$ hours. 
Figure 12. Fructose conversion in 5-HMF using concentrated aqueous solutions of different carboxylic acids as reactive solvent.

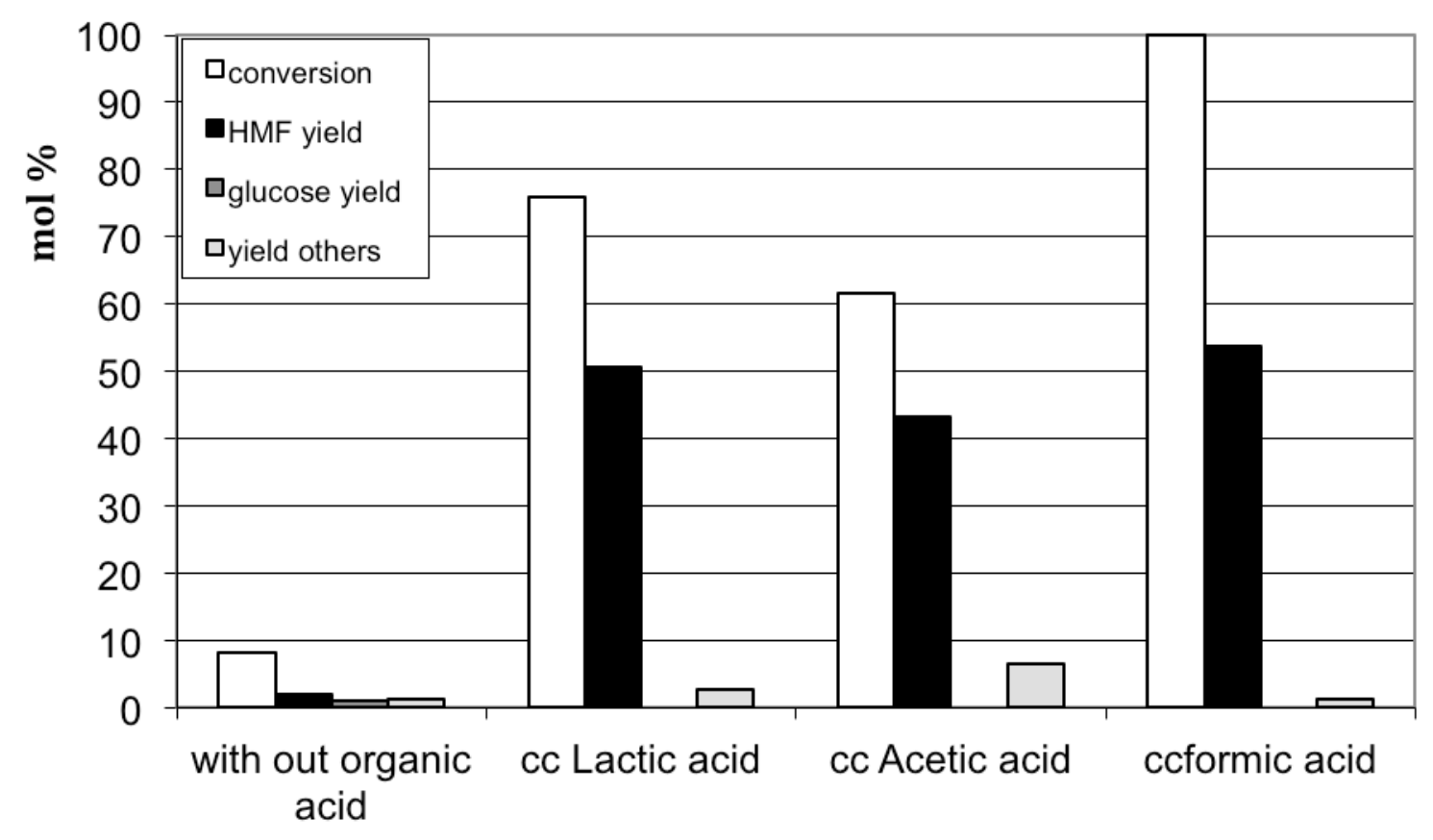

Conditions: Batch conditions, fructose $1 \% \mathrm{wt}, 20 \mathrm{wt} \%$ of organic acid in water, $150{ }^{\circ} \mathrm{C}, 2$ hours.

To our surprise, we observed that the presence in water of $20 \mathrm{wt} \%$ of acetic or formic acids also led to high 5-HMF yields of 43-53\%. Figures 13-15 show the influence of the carboxylic acid concentration for acetic acid, formic acid and lactic acid respectively. One can observe that the presence of water in the medium is necessary, since a dramatic drop in 5-HMF yields was observed when pure carboxylic acids were used. This is probably due to the too-strong acidy of the anhydrous media. In this last case, other acid catalyzed reactions can readily occur, such as esterification of 5-HMF and certainly some 5-HMF oligomerization formed via an acid catalyzed mechanism since most of the products were not detected by HPLC. Note however that we did not observe the formation of the ester of 5-HMF when water is present in the medium. Indeed, this seems to be a prerequisite to obtain selectively 5-HMF using concentrated liquid organic acids as media. The best result is obtained in a $50 \mathrm{wt} \%$ lactic acid solution leading to a 5-HMF yield of $64 \%$, certainly one of the highest 5-HMF yield obtained in a single phase, free of 5-MHF extractive solvent.

These results show that carboxylic acids, which are weak acids, possess the required acidity to convert fructose efficiently into 5-HMF without significant transformation of the latter. The $\mathrm{pH}$ of $20 \mathrm{wt} \%$ acetic acid in water is 1.7 . This fits well with the narrow $\mathrm{pH}$ range shown to favor the 5-HMF formation in equivalent conditions (Figure 3). This result is also in agreement with the earlier work of Kuster et al. [16], showing that the 5-HMF formation is strongly $\mathrm{pH}$ dependent. Moreover, organic acids such as acetic and formic acids can be easily eliminated from the reaction media due to their relative high volatility. Finally, this way is of high importance, since we can simply preclude the use of 5-HMF extractive solvents which can cause problems at the industrial scale. 
Figure 13. Fructose conversion in 5-HMF obtained in acetic acid aqueous solutions of various compositions in the absence of added solid catalyst.

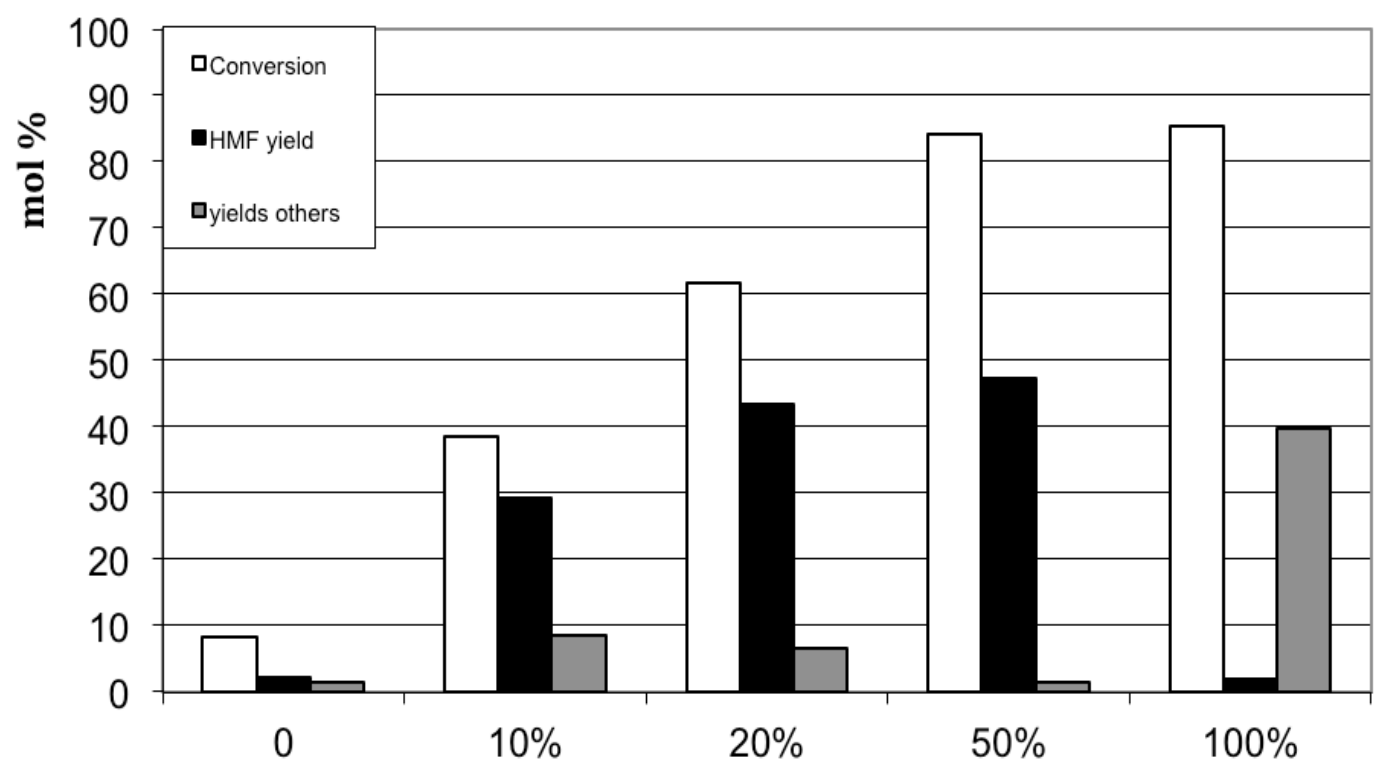

Conditions: Batch conditions: fructose $1 \% \mathrm{wt}$, variable amounts of acetic acid in water, $150{ }^{\circ} \mathrm{C}$, 2 hours.

Figure 14. Fructose dehydration in 5-HMF obtained in formic acid aqueous solutions of various compositions in the absence of added solid catalyst.

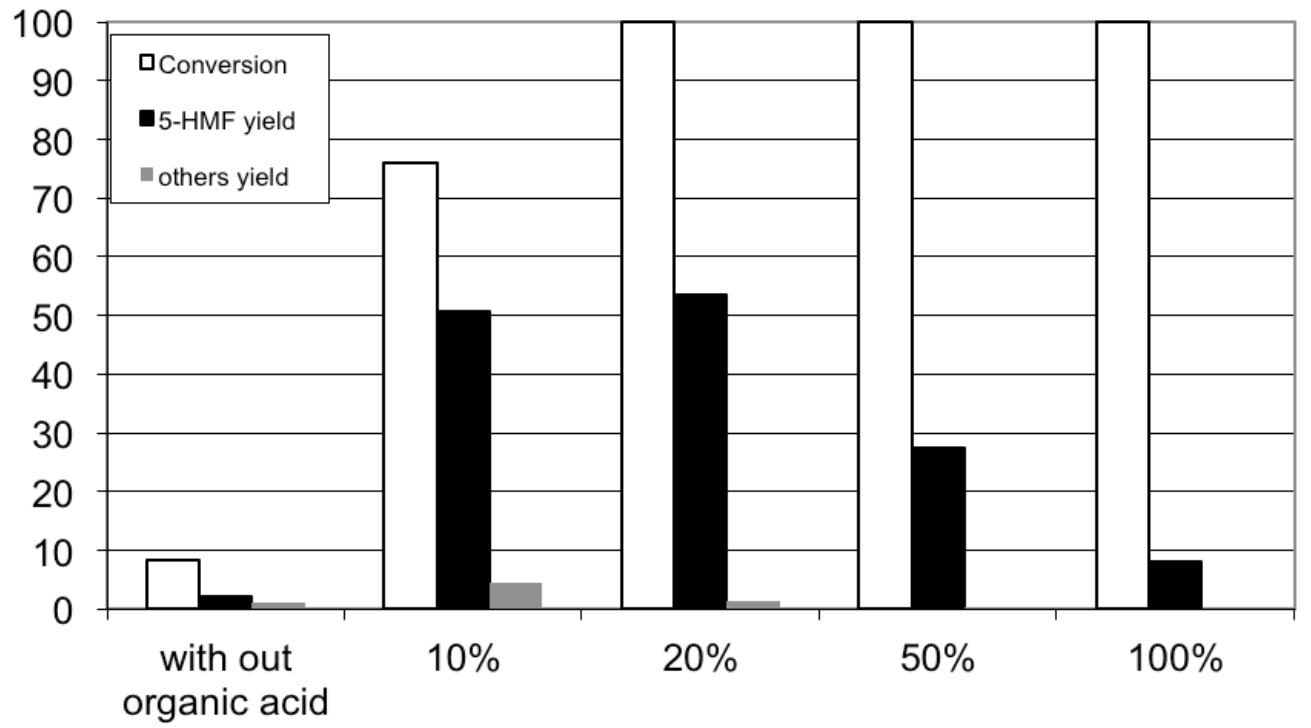

Conditions: Batch conditions: fructose $1 \% \mathrm{wt}$, variable amounts of formic acid in water, $150{ }^{\circ} \mathrm{C}$, 2 hours.

We have shown that the aqueous concentrated organic acid solutions provide a medium for the optimum acidity for 5-HMF formation, starting from fructose. However, since these media do not dehydrate glucose, which, in principle, requires a preliminary isomerization in fructose, it seems reasonable to conclude that the weak Brønsted acidity of these media does not promote glucose isomerization. 
Figure 15. Fructose dehydration in 5-HMF obtained in lactic acid aqueous solutions of various compositions in the absence of added solid catalyst.

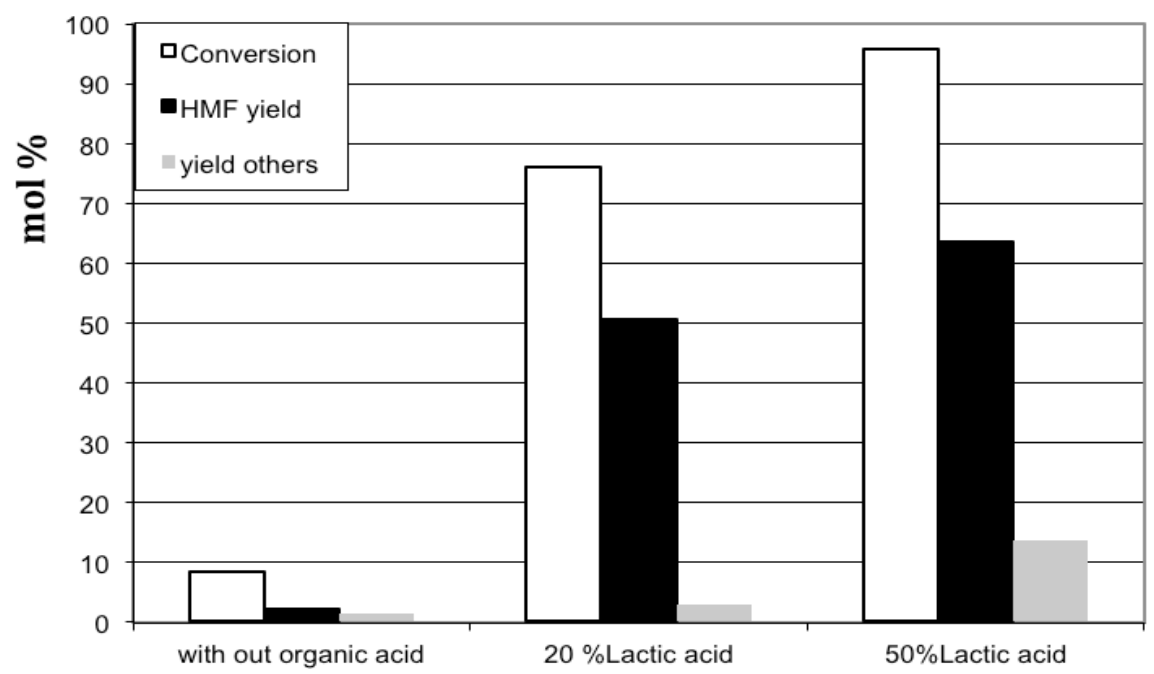

Conditions: Batch conditions: fructose $1 \% \mathrm{wt}$, variable amounts of Lactic acid in water, $150{ }^{\circ} \mathrm{C}$, 2 hours.

Therefore, these first results prompted us to add solid catalysts in the media, which might catalyze the glucose isomerization. Solid Lewis acids: AlW, Sn-Beta, $\mathrm{ZrW}$ or a solid base, MgLaO. In addition, we tested the influence of the presence of solid acids with Brønsted acidity (heteropolyacids, sulfonated carbon) or with Brønsted and Lewis sites $\left(\mathrm{H}_{3} \mathrm{PO}_{4} / \mathrm{NbOH}\right)$. The idea was to check the possibility to get 5-HMF starting from glucose by combining a heterogeneous acid function of various strengths and the homogeneous weak Brønsted acidity brought by the liquid carboxylic acids medium. Our preliminary results are summarized in Figure 16. In some cases, in the presence of tungstated oxides $\mathrm{AlW}, \mathrm{ZrW}$ or of $\mathrm{H}_{3} \mathrm{PO}_{4} / \mathrm{NbOH}$, the glucose conversion is improved, together with 5-HMF yield, but the results remain modest. Work is still in progress to go further in that direction to clarify and explain these preliminary results.

Figure 16. Glucose conversion in $20 \mathrm{wt} \%$ acetic acid aqueous solutions in the presence of added solid catalysts.

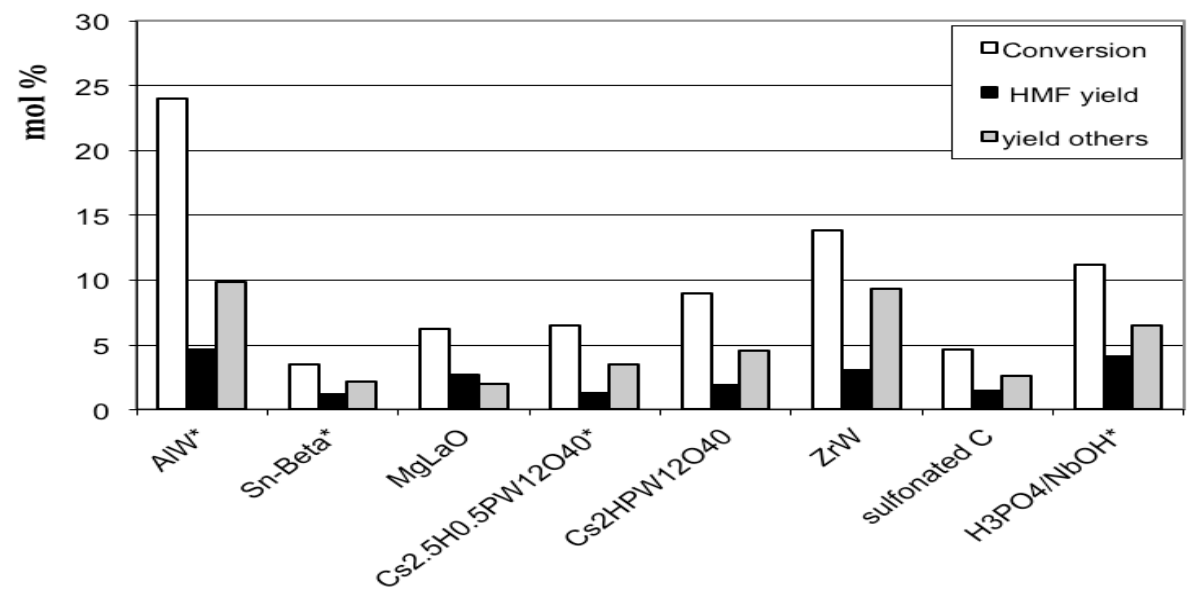

Conditions: Batch conditions: glucose $1 \% \mathrm{wt}, 150{ }^{\circ} \mathrm{C}, 2$ hours, media: $20 \mathrm{wt} \%$ acetic acid in water solid catalyst: $5 \mathrm{wt} \% /$ glucose, ${ }^{*} 10 \mathrm{wt} \% /$ glucose 


\section{Experimental Section}

Glucose, fructose, 5-HMF and carboxylic acids were obtained from Aldrich and used as received. The catalysts $\mathrm{Cs}_{2} \mathrm{HPW}_{12} \mathrm{O}_{40}, \mathrm{ZrW}$ (W $12 \% \mathrm{wt}$ ), $\mathrm{ZrO}_{2}, \mathrm{ZrCs}$ (Cs $3.3 \% \mathrm{wt}$ ), were prepared according to published methods [32,40]. ZrMg was prepared by a dropwise impregnation $10 \mathrm{~g}$ of zirconium hydroxide with a $9 \mathrm{~mL}$ aqueous solution of $\mathrm{Mg}\left(\mathrm{NO}_{3}\right)_{2}(1 \mathrm{~g})$ and evaporation of water at $60{ }^{\circ} \mathrm{C}$ followed by a calcination (air, $550{ }^{\circ} \mathrm{C}, 2$ hours) of the obtained solid. Niobic acid (HY-340 hydrated niobium oxide) was obtained from CBBM. HY and Y-ZSM-5 were commercial samples.

Reactions were performed in a $100 \mathrm{~mL}$ batch autoclave using a Teflon insert and equipped with an internal thermocouple. The aqueous organic acid solutions were prepared by addition of the organic acid to water solutions of hexose. After introduction of the mixture, the reactor was flushed with $\mathrm{He}$ before heating $\left(10{ }^{\circ} \mathrm{C} / \mathrm{min}\right)$. The reaction medium was stirred using a magnetic stirrer under autogeneous pressure. The reaction mixture was analyzed on a Shimadzu HPLC system equipped with a RID (Coregel $87 \mathrm{C}$ column, $80^{\circ} \mathrm{C}$, water as eluent). In addition to 5-HMF, the following products were identified and quantified: mannose, levulinic acid, formic acid, lactic acid, acetol. Some products were detected by HPLC but not identified. In that case, the response coefficient of 5-HMF was applied. The sum of these products was abbreviated "other products". All given yields are molar yields. The relative error on the hexoses conversion and 5-HMF yield is $5 \%$.

FTIR spectra of self-supported pellets of $\mathrm{NbOH}$ ) were recorded with a Brucker Vector 22 spectrometer in absorption mode with a resolution of $2 \mathrm{~cm}^{-1}$. The samples were placed in an IR cell equipped with $\mathrm{CaF}_{2}$ windows and treated in situ. The wafer of $\mathrm{Nb}$-based samples was pretreated at $400{ }^{\circ} \mathrm{C}$. Pyridine was adsorbed under saturation vapor pressure at ambient temperature, then desorbed at $150{ }^{\circ} \mathrm{C}$ for 1 hour in order to remove the physisorbed species.

\section{Conclusions}

We first reported in this paper our results on the hydrothermal conversion of glucose and fructose, in batch conditions, varying the reaction conditions, temperature and acidity, in the presence of a large panel of usual solid catalysts. First, we showed that relatively high 5-HMF yield can be achieved via a fine tuning of the $\mathrm{pH}$ of the aqueous solution between the values 1.5 and 1.9. A variety of catalysts with various acid-base features were employed. We showed that whatever the catalytic system, limited yields of $20-30 \%$ in 5 -HMF were obtained in batch conditions with the most efficient solid acid catalyst, $\mathrm{NbOH}$, used in large amounts, far from the catalytic one. Anyway, these results confirmed that the use of pure water as solvent in the presence of solid acids does not permit an easy formation of 5-HMF, due to the reactivity of 5-HMF.

We then reported our first results concerning the use of concentrated aqueous solutions of liquid carboxylic acids as reactive reaction media for this transformation. The presence of $10-50 \mathrm{wt} \%$ of formic, acetic or lactic acids in water gave high conversion of fructose with 5-HMF yields up to 64\%, indicating that these aqueous solutions present the adequate acidity to promote this reaction. However, these reactive media are unable to convert glucose. Our preliminary results dealing with the addition of solid catalysts in these media which would promote the glucose isomerization into fructose, such as Lewis or basic solid catalysts, did not give the expected results in batch conditions. 
Nevertheless, these solvent systems, which are clean and green, deserve a deeper attention and further studies are currently performed to address in detail the influence of external catalyst addition while optimizing the reaction conditions.

\section{Acknowledgments}

The authors thank the CNRS, the University of Lyon 1 and the French Research National Agency (POLYGLU Project) for funding.

\section{References and Notes}

1. Bicker, M.; Hirth, J.; Vogel, H. Dehydration of fructose to 5-hydroxymethylfurfural in sub- and supercritical acetone. Green Chem. 2003, 5, 280-284.

2. Rosatella, A.A.; Simeonov, S.P.; Frade, R.F.M.; Afonso, C.A.M. 5-Hydroxymethylfurfural (HMF) as a building block platform: Biological properties, synthesis and synthetic applications. Green Chem. 2011, 13, 754-793.

3. Stahlberg, T.; Fu, W.; Woodley, J.M.; Riisager, A. Synthesis of 5-(Hydroxymethyl)furfural in Ionic Liquids: Paving the way to renewable chemicals. ChemSusChem 2011, 4, 451-458.

4. Tong, X.; Ma, Y.; Li, Y. Biomass into chemicals: Conversion of sugars to furan derivatives by catalytic processes. Appl. Cata. A 2010, 385, 1-13.

5. Vigier, K.; Jerome, F. Heterogeneously-catalyzed conversion of carbohydrates. Top. Curr. Chem. 2010, 255, 63-92.

6. Lightner, G.E. US 20020123636 A1 20020905, U.S. Pat. 2002.

7. Sanborn, A.J.; Bloom, P.D. US 7393963 B2 20080701, 2008.

8. Gaset, A.; Rigal, L.; Paillassa, G.; Salome, J.-P.; Fleche, G. FR 2551754 A1 19850315, 1985.

9. Chheda, J.N.; Dumesic, J.A. An overview of dehydration, aldol-condensation and hydrogenation processes for production of liquid alkanes from biomass-derived carbohydrates. Catal. Today 2007, 123, 59-70.

10. Watanabe, M.; Aizawa, Y.; Iida, T.; Nishimura, R.; Inomata, H. Catalytic glucose and fructose conversions with $\mathrm{TiO}_{2}$ and $\mathrm{ZrO}_{2}$ in water at $473 \mathrm{~K}$ : Relationship between reactivity and acid-base property determined by TPD measurement. Appl. Catal. A 2005, 295, 150-156.

11. Moreau, C.; Finiels, A.; Vanoye, L. Dehydration of fructose and sucrose into 5-hydroxymethylfurfural in the presence of 1-H-3-methyl imidazolium chloride acting both as solvent and catalyst. J. Mol. Catal. A 2006, 253, 165-169.

12. Zhao, H.; Holladay, J.E.; Brown, H.; Zhang, Z.C. Metal chlorides in ionic liquid solvents convert sugars to 5-hydroxymethylfurfural. Science 2007, 316, 1597-1600.

13. Pidko, E.A.; Degirmenci, V.; van Santen, R.A.; Hensen, E.J.M. Glucose activation by transient $\mathrm{Cr}^{2+}$ dimers. Angew. Chem. Int. Ed. 2010, 49, 2530-2534.

14. Hu, S.; Zhang, Z.; Song, J.; Zhou, Y.; Han, B. Efficient conversion of glucose into 5-hydroxymethylfurfural catalyzed by a common Lewis acid $\mathrm{SnCl}_{4}$ in an ionic liquid. Green Chem. 2009, 11, 1746-1749.

15. Mittal, N.; Nisole, G.M.; Chung, W.J. Facile catalytic dehydration of fructose to 5-hydroxymethylfurfural by Niobium pentachloride. Tetrahedron 2012, 53, 3149-3155. 
16. Kuster, B.F.M.; Temmink, H.M.G. The dehydration of D-fructose (formation of 5-hydroxymethyl-2-furaldehyde and levulinic acid): Part IV. The influence of $\mathrm{pH}$ and weak-acid anions on the dehydration of D-fructose. Carbohydr. Res. 1977, 54, 185-191.

17. Armaroli, T.; Busca, G.; Carlini, C.; Giuttari, M.; Raspolli Galletti, A.M.; Sbrana, G. Acid site characterization of niobium phosphate catalysts and their activity in fructose dehydration to 5-hydroxymethyl-2-furaldehyde. J. Mol. Catal. A 2000, 151, 233-243.

18. Carlini, C.; Patrono, P.; Raspolli Galletti, A.M.; Sbrana, G. Heterogeneous catalysts based on vanadyl phosphate for fructose dehydration to 5-hydroxymethyl-2-furaldehyde. Appl. Catal. A 2004, 275, 111-118.

19. Benvenuti, F.; Carlini, C.; Patrono, P.; Raspolli Galletti, A.M.; Sbrana, G.; Massucci, M.A.; Galli, P. Heterogeneous zirconium and titanium catalysts for the selective synthesis of 5-hydroxymethyl-2-furaldehyde from carbohydrates. Appl. Catal. A 2000, 193, 147-153.

20. Hansen, T.S.; Mielby, J.; Riisager, A. Synergy of boric acid and added salts in the catalytic dehydration of hexoses to 5-hydroxymethylfurfural in water. Green Chem. 2011, 13, 109-114.

21. Kitano, M.; Nakajima, K.; Kondo, J.N.; Hayashi, S.; Hara, M. Protonated titanate nanotubes as solid acid catalyst. J. Am. Chem. Soc. 2010, 132, 6622-6623.

22. Nakajima, K.; Baba, Y.; Noma, R.; Kitano, M.; Kondo, J. N.; Hayashi, S.; Hara, M. $\mathrm{Nb}_{2} \mathrm{O}_{5} \cdot \mathrm{nH}_{2} \mathrm{O}$ as a Heterogeneous Catalyst with Water-Tolerant Lewis Acid Sites. J. Am. Chem. Soc. 2011, 133, 4224-4227.

23. Dutta, S.; de, S.; Patra, A.K.; Sasidharan, M.; Bhaumik, A.; Saha, B. Microwave assisted rapid conversion of carbohydrates into 5-hydroxymethylfurfural catalyzed by mesoporous $\mathrm{TiO}_{2}$ nanoparticles. Appl. Catal. A 2011, 409-410, 133-139.

24. Yang, F.; Liu, Q.; Min, Y.; Bai, X.; Du, Y. Tantalum compounds as heterogeneous catalysts for saccharide dehydration to 5-hydroxymethylfurfural. Chem. Commun. 2011, 47, 4469-4471.

25. Roman-Leshkov, Y.; Moliner, M.; Labinger, J.A.; Davis, M.E. Mechanism of glucose isomerization using a solid lewis acid catalyst in water. Angew. Chem. Int. Ed. 2010, 49, 8954-8957.

26. Jensen, V.J.; Rugh, S. Industrial-scale production and application of immobilized glucose isomerase. Methods Enzymol. 1987, 136, 356-370.

27. Buchholz, K.; Seibel, J. Industrial carbohydrate biotransformations. Carbohydr. Res. 2008, 343, 1966-1979.

28. Lobry de Bruyn, C.A.; Alberda van Ekenstein, W. Action of alkalis on the sugars. Reciprocal transformation of glucose, fructose, and mannose. Recueil des Travaux Chimiques des Pays-Bas 1895, 14, 201-16.

29. Lima, S.; Dias, A.S.; Lin, Z.; Brandao, P.; Ferreira, P.; Pillinger, M.; Rocha, J.; Calvino-Casilda, V.; Valente, A.A. Isomerization of D-glucose to D-fructose over metallosilicate solid bases. Appl. Catal. A 2008, 339, 21-27.

30. Cornille, F. FR 2862973 A1 20050603, 2005.

31. Moreau, C.; Durand, R.; Roux, A.; Tichit, D. Isomerization of glucose into fructose in the presence of cation-exchanged zeolites and hydrotalcites. Appl. Catal. A 2000, 193, 257-264.

32. Souza, R.O.L.; Patrick, D.F.; Feche, C.; Cardoso, D.; Rataboul, F.; Essayem, N. Glucose-fructose isomerization promoted by basic hybrid catalysts. Catal. Today 2012, In Press, doi: 10.1016/j.cattod.2012.05.046. 
33. Moreau, C.; Lecomte, J.; Roux, A. Determination of the basic strength of solid catalysts in water by means of a kinetic tracer. Catal. Commun. 2006, 7, 941-944.

34. Ohara, M.; Takagaki, A.; Nishimura, S.; Ebitani, K. Syntheses of 5-hydroxymethylfurfural and levoglucosan by selective dehydration of glucose using solid acid and base catalysts. Appl. Catal. A 2010, 383, 149-155.

35. Avignon, G.; Durand, R.; Faugeras, P.; Geneste, P.; Moreau, C.; Rivalier, P.; Ros, P. FR 2670209 A1 19920612, 1992.

36. Carlini, C.; Giuttari, M.; Raspolli Galletti, A.M.; Sbrana, G.; Armaroli, T.; Busca, G. Selective saccharide dehydration to 5-(hydroxymethyl)-2-furaldehyde by heterogeneous niobium catalysts. Appl. Catal. A 1999, 183, 295-302.

37. Carlini, C.; Patrono, P.; Raspolli Galletti, A.M.; Sbrana, G. Heterogeneous catalysts based on vanadyl phosphate for fructose dehydration to 5-hydroxymethyl-2-furaldehyde. Appl. Catal. A 2004, 275, 111-118.

38. Carniti, P.; Gervasini, A.; Biella, S.; Auroux, A. Niobic acid and niobium phosphate as highly acidic viable catalysts in aqueous medium: Fructose dehydration reaction. Catal. Today 2006, $118,373-378$.

39. Qi, X.; Watanabe, M.; Aida, T.M.; Smith, R.L., Jr. Catalytical conversion of fructose and glucose into 5-hydroxymethylfurfural in hot compressed water by microwave heating. Catal. Commun. 2008, 9, 2244-2249.

40. Chambon, F.; Rataboul, F.; Pinel, C.; Cabiac, A.; Guillon, E.; Essayem, N. Cellulose hydrothermal conversion promoted by heterogeneous Bronsted and Lewis acids: Remarkable efficiency of solid Lewis acids to produce lactic acid. Appl. Catal. B 2011, 105, 171-181.

41. Desmartin-Chomel, A.; Hamad, B.; Palomeque, J.; Essayem, N.; Bergeret, G.; Figueras, F. Basic properties of $\mathrm{MgLaO}$ mixed oxides as determined by microcalorimetry and kinetics. Catal. Today 2010, 152, 110-114.

42. Essayem, N.; Lopes de Souza, R.; Rataboul, F.; Patrick, D.F.; Feche, C.; Cardoso, D. FR 1157575 11, 2011.

43. Carniti, P.; Gervasini, A.; Marzo, M. Absence of expected side-reactions in the dehydration reaction of fructose to HMF in water over niobic acid catalyst. Catal. Commun. 2011, doi: 10.1016/j.catcom.2011.03.025

44. Antal, M.J., Jr.; Mok, W.S.L.; Richards, G.N. Kinetic studies of the reactions of ketoses and aldoses in water at high temperature. 1. Mechanism of formation of 5-(hydroxymethyl)-2furaldehyde from D-fructose and sucrose. Carbohydr. Res. 1990, 199, 91-109.

45. Garber, J.D.; Jones, R.E. US 2929823 19600322, 1960.

46. Essayem, N.; Lopes de Souza, R.; Rataboul, F. FR 11/54232.

(C) 2012 by the authors; licensee MDPI, Basel, Switzerland. This article is an open access article distributed under the terms and conditions of the Creative Commons Attribution license (http://creativecommons.org/licenses/by/3.0/). 